\title{
Narrative Review \\ Effect of Exercise on Immunological Indicators During the COVID-19 Pandemic
}

\author{
Amir Hossein Ahmadi Hekmatikar ${ }^{1}\left[{ }^{\circ},{ }^{*}\right.$ Mahdieh Molanouri Shamsi ${ }^{1}$ (i)
}

1. Department of Physical Education, Faculty of Humanities, Tarbiat Modares University, Tehran, Iran.

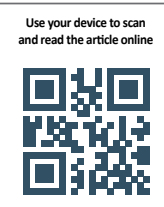

Citration: Ahmadi Hekmatikar AH, Molanouri Shamsi M. [Effect of Exercise on Immunological Indicators During the COVID-19 Pandemic (Persian)]. Journal of Arak University of Medical Sciences (JAMS). 2020; 23(5):584-603. https://doi. org/10.32598/JAMS.23.COV.6277.1

doi https://doi.org/10.32598/JAMS.23.COV.6277.1

Key words:

Coronavirus, Physical activity, COVID-19

\section{ABSTRACT}

Article Info:

Received: 19 Aug 2020

Accepted: 22 Sep 2020

Available Online: 01 Dec 2020
Background and Aim Coronavirus Disease 2019 (COVID-19), as a viral disease, has increasingly highlighted the need for lifelong exercise due to its immunological and physiological effects is necessary on health. In this review study, while examining the effects of moderate-intensity exercise on the physiological and immunological responses associated with COVID-19, appropriate exercise patterns during the COVID-19 pandemic are presented.

Methods \& Materials In this study, the search was conducted in Web of Science, Scopus, ISC, PubMed, Google Scholar, MagIran, and Noor databases on related articles using the following keywords: coronavirus, COVID-19, exercise and coronavirus, exercise and immune system, high-intensity exercise and immune system.

Ethical Considerations All ethical principles in writing this article have been observed according to the instructions of the National Ethics Committee and the COPE regulations.

Results: Moderate-intensity exercise can help boost the function of the immune system. On the other hand, high-intensity exercise can have negative effects on the immune system, which can be a bad strategy increasing the risk of infectious diseases.

Results Moderate-intensity exercise can help boost the function of the immune system. On the other hand, high-intensity exercise can have negative effects on the immune system, which can be a bad strategy increasing the risk of infectious diseases.

Conclusion Due to the onset of the second wave of COVID-19 in the world, it is recommended to continue to exercise at home observing the hygiene rules (maintaining humidity and disinfecting environmental surfaces) and using appropriate intensity and duration.

\section{Extended Abstract}

\section{Introduction}

n late December 2019, a disease called coronavirus disease 2019 (COVID-9) was identified in Wuhan, China, which spread rapidly around the world. Its virus was first found in seafoods in Wuhan, China [1, 2]. COVID-9 can severely affect the immune system and affect many tissues, especially the lungs, by causing cytokine storms in the body [8]. On the other hand, it has been shown that exercise can increase the function of the immune system [15]. People are still active at different intensities during the COVID-9 pandemic. This study aims to review the effect of different inten-

\section{* Corresponding Author:}

Mahdieh Molanouri Shamsi, PhD.

Address: Department of Physical Education, Faculty of Humanities, Tarbiat Modares University, Tehran, Iran. Tel: +98 (21) 82884683

E-mail: molanouri@modares.ac.ir 
sities of exercise on the immune system, and consequently on COVID-9.

\section{Materials and Methods}

This is a review study. The search was conducted in Scopus ،ISC, PubMed, Google Scholar, MagIran, and Noor databases on related studies published from 1995 to 2020 by using following keywords: Coronavirus, COVID-9, exercise and coronavirus, exercise and immune system, high-intensity exercise and immune system, moderate-intensity exercise and immune system, low-intensity exercise and immune system. The inclusion criteria were: publishing in Persian or English, and in journals with higher impact factor or reputable national journals. The exclusion criteria were: publishing in blacklisted or hijacked journals, publishing at conferences, and being duplicate or unrelated study.

\section{Results}

With the outbreak of COVID-9, many physiological changes occurred in the body including a impairment in the immune system and a rapid increase in obesity, depression and cardiovascular problems [10]. It has been shown that exercise can reduce the risk of these problems [13, 14]. However, the intensity of exercise is a major factor. High-intensity exercise can increase cortisol and lower the immune system function, while moderate-intensity exercise can improve immune function, reduce weight, and so on [15]. In general, it can be said that exercise is an effective strategy to make positive changes in the physiological process of the body during the COVID-9 pandemic. Studies have shown that exercise can increase endorphins and reduce depression. In a study, sudden stop of exercise caused professional athletes to become depressed; that is why researchers stated that moderate-intensity exercise can be very effective [35].

Preliminary epidemiological data have shown that cardiovascular diseases are very common following a significant increase in disease severity and mortality in people who are inactive and obese. Cardiovascular benefits of regular exercise include a reduction in resting heart rate and blood pressure, improved respiration, weight loss, and other metabolic changes that can lead to improved lipid profiles and glucose tolerance [43]. Undoubtedly, these factors are important and justify the constant emphasis on regular exercise as a major part of prevention and treatment goals. Studies have also reported that moderate-intensity exercise to be a very good factor in increasing fat oxidation. High-intensity exercise can also inhibit lipolysis. In this regard, Khoramipour et al. on their review study stated that the highest rate of fat oxidation occurs at low to moderate intensities between 35 to $65 \%$ VO${ }_{2} \max [50]$. Therefore, it can be said that moderate-intensity exercise during the COVID-9 pandemic can cause weight loss.

Exercise can act like a medicine in the body. Numerous studies have shown that exercise and physical activity can have anti-inflammatory effects [56-59] and help improve the immune system and increase T cells in the body [56]. For athletes who perform moderate to high-intensity exercises, it is recommended to use liquid carbohydrates during competition to prevent a weakened immune system and increased interleukin-10 level [61]. In this regard, regular exercise can have an anti-inflammatory effect on the body, such that exercise has been shown to improve the immune response to influenza vaccine in the elderly [55].

\section{Discussion and Conclusion}

Due to the outbreak of COVID-9 and increased home stay, performing exercise along with simple movements can improve the function of the immune and cardiovascular systems. According to numerous reports of the effect of highintensity exercises on lowering the function of the immune system, it is better to perform moderate-intensity exercises (for 30-45 min). It is also recommended to control the house humidity during indoor exercise indoors. Finally, people with severe colds or COVID-9 are better to refrain from exercise until they are fully recovered.

\section{Ethical Considerations}

\section{Compliance with ethical guidelines}

In writing this article, ethical principles were considered in accordance with the instructions of the National Ethics Committee and the COPE regulations.

\section{Funding}

This study was approved by the Vice-Chancellor for Research and Technology, Tarbiat Modares University.

\section{Authors' contributions}

The authors observed the criteria of the International Committee of Medical Journal Editors (ICMJE).

\section{Conflicts of interest}

The authors declare no conflict of interest.

\section{Acknowledgements}

The authors would like to thank the Research Center of Tarbiat Modares University (TMU). 
This Page Intentionally Left Blank 


\section{اثرات فعاليت ورزشى با رعايت يروتكلهاي بهراشتى بر شاخص هائ ايمونولوزيك در دوران شيوع بيمارى كوويد 19: مرورى رواتيث روايتى \\ اميرحسين احمدى حكمتى كار' (1)، "مهديه ملانورى شمسى' \\ 1. ا.كروه تربيتبدنى، دانشكده علوم انسانى، دانشعاه تربيت مدرس، تهران، ايران.}

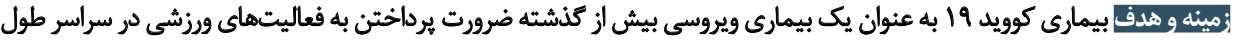

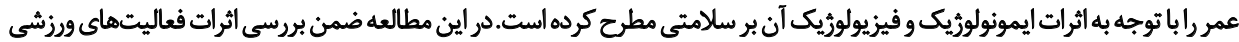

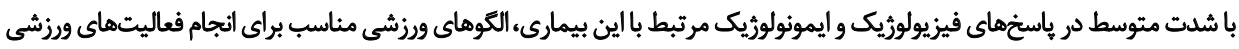
در دوران شيوع اين بيمارى ارائه شده استر

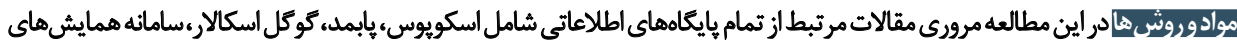

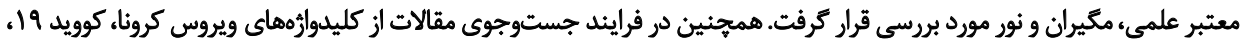

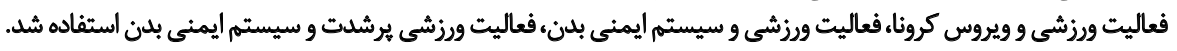

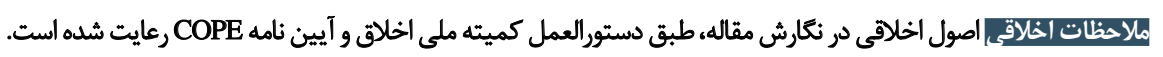

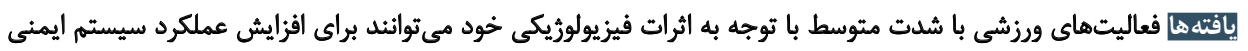

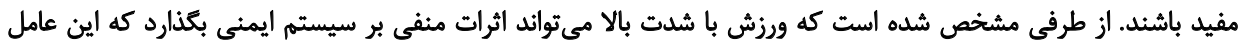

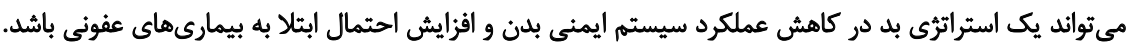

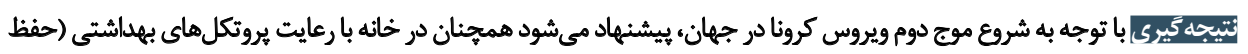

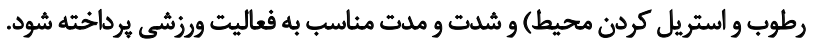

اطلاعات مقاله:

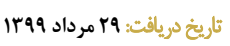

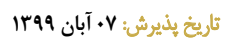

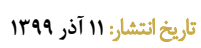

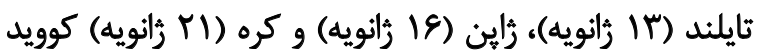

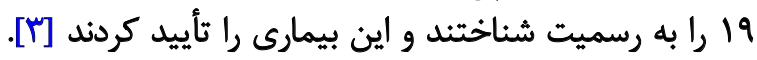

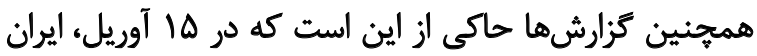
كرد VAY

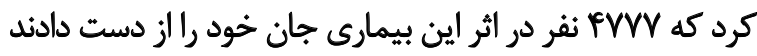

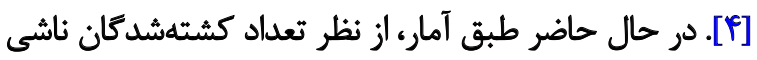

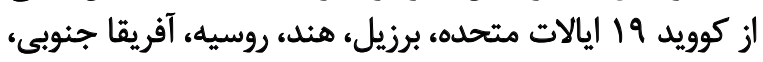

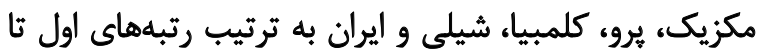

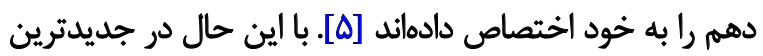
كزارشات سازمان بهداشت جهانى، ايران در رتبه دهم جاد جائ كرفته

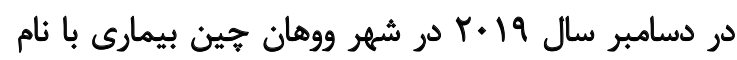

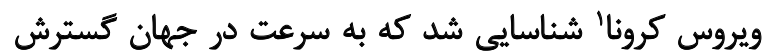

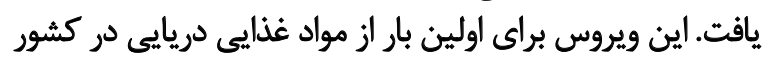

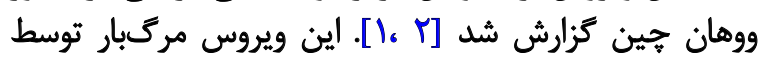

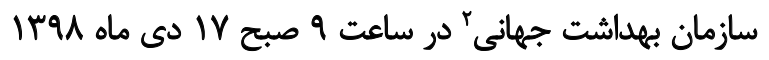

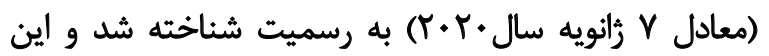

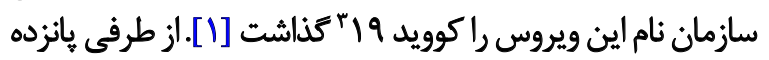

1. Coronavirus

2. World Health Organization (WHO)

3. Covid-19 


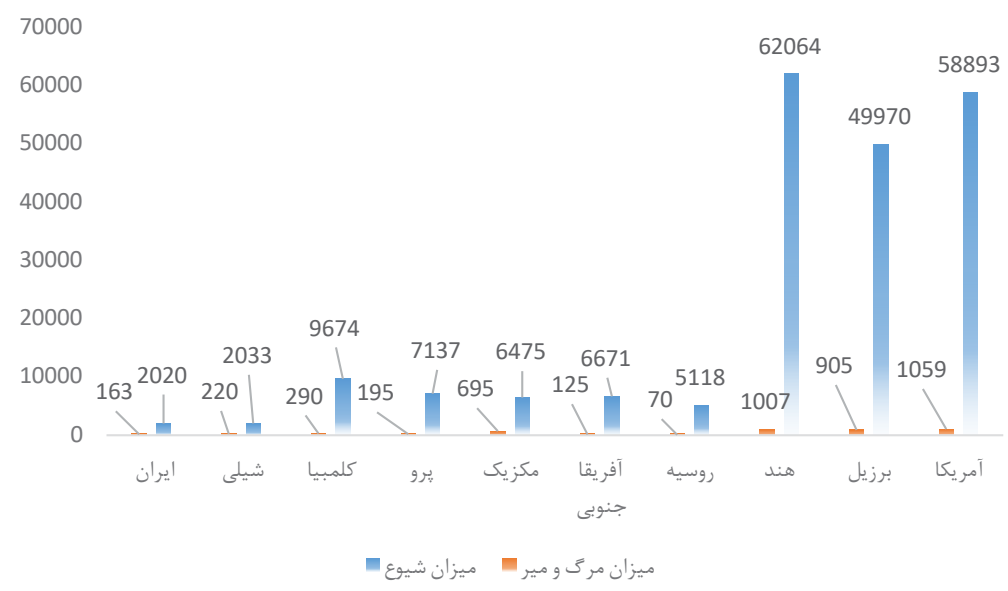

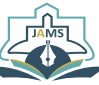

فعاليت ورزشى و ويروس كرونا ، فعاليت ورزشى و سيستم ايمنى

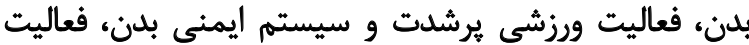

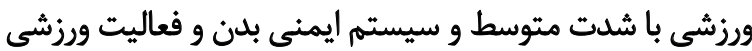

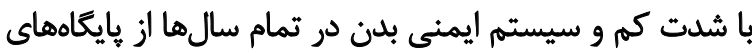

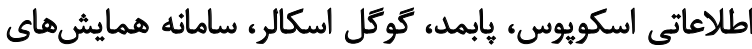

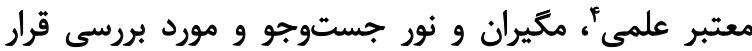

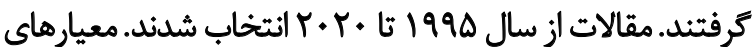
ورود و خروج به تحقيق حاضر به شرح زير بود: ا. مقالات به زبان فارسى يا انكُليسى باشند (مقالاتى به جز اين

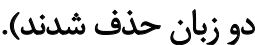
Y. مقالات انتليسى و فارسىزبان از مجلاتى كه در ليست سياه، در فهرست زورنال هاي هايجكش

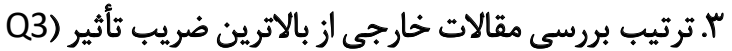

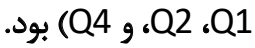

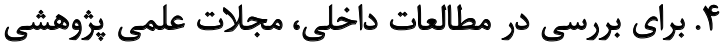

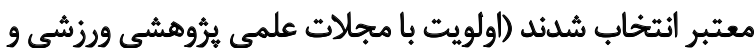
سيس مجلات علوميزشكى بود). ه. مقالاتى كه در مجلات علمى ترويجى، همايش و كنفرانس

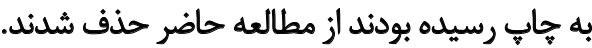
9. براى به حداكثر رساندن جامعيت جستوجو در اين مطالعه

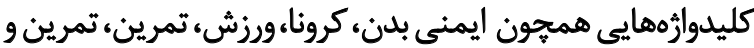

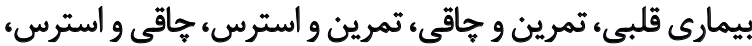

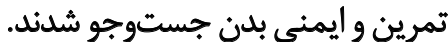
V. مطالعات تكرارى يا غيرمرتبط با موضوع تحقيق حاضر از تحقيق حذف شد.

4. Islamic World Science Citation Center (ISC)

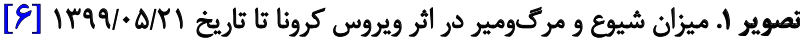
است، ولى همجنان جزء ده كشور خطرناك محسوب مىشود

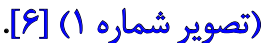

به صورت طبيعى، عفونتهاى ويروسى با عفونتهاى دستًاه

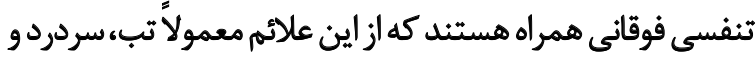

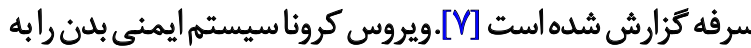

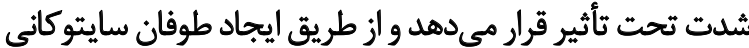

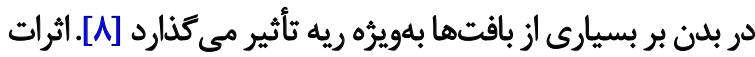

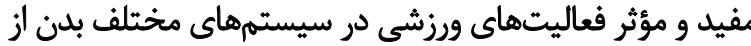

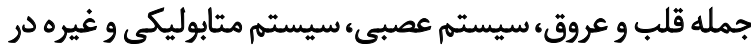

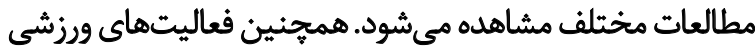

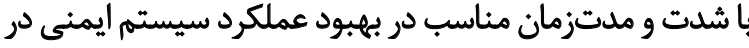

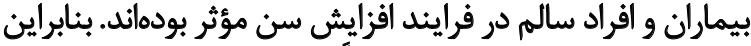

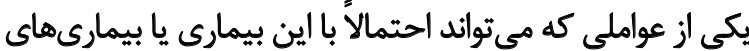

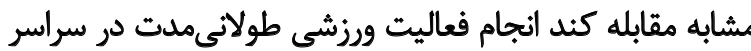

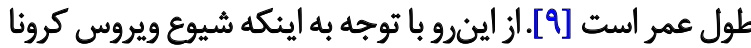

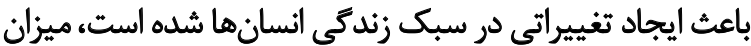

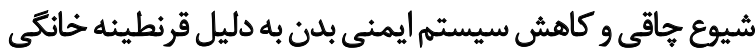

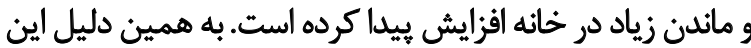

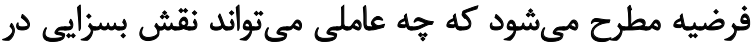

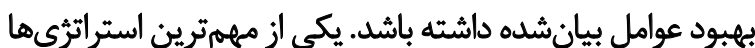

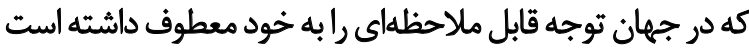

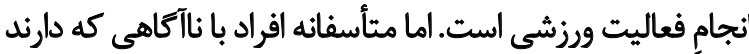

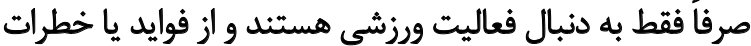

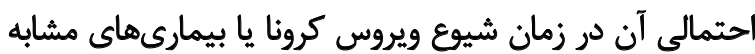

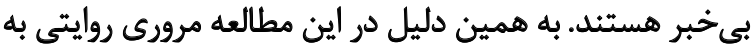
بررسى تأثير فعاليت ورزشى بر ويروس كرونا برداخته شد.

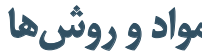

مطالعه حاضر يك تحقيق مرورى است. در اين مطالعه مقالات

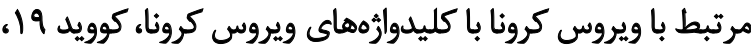




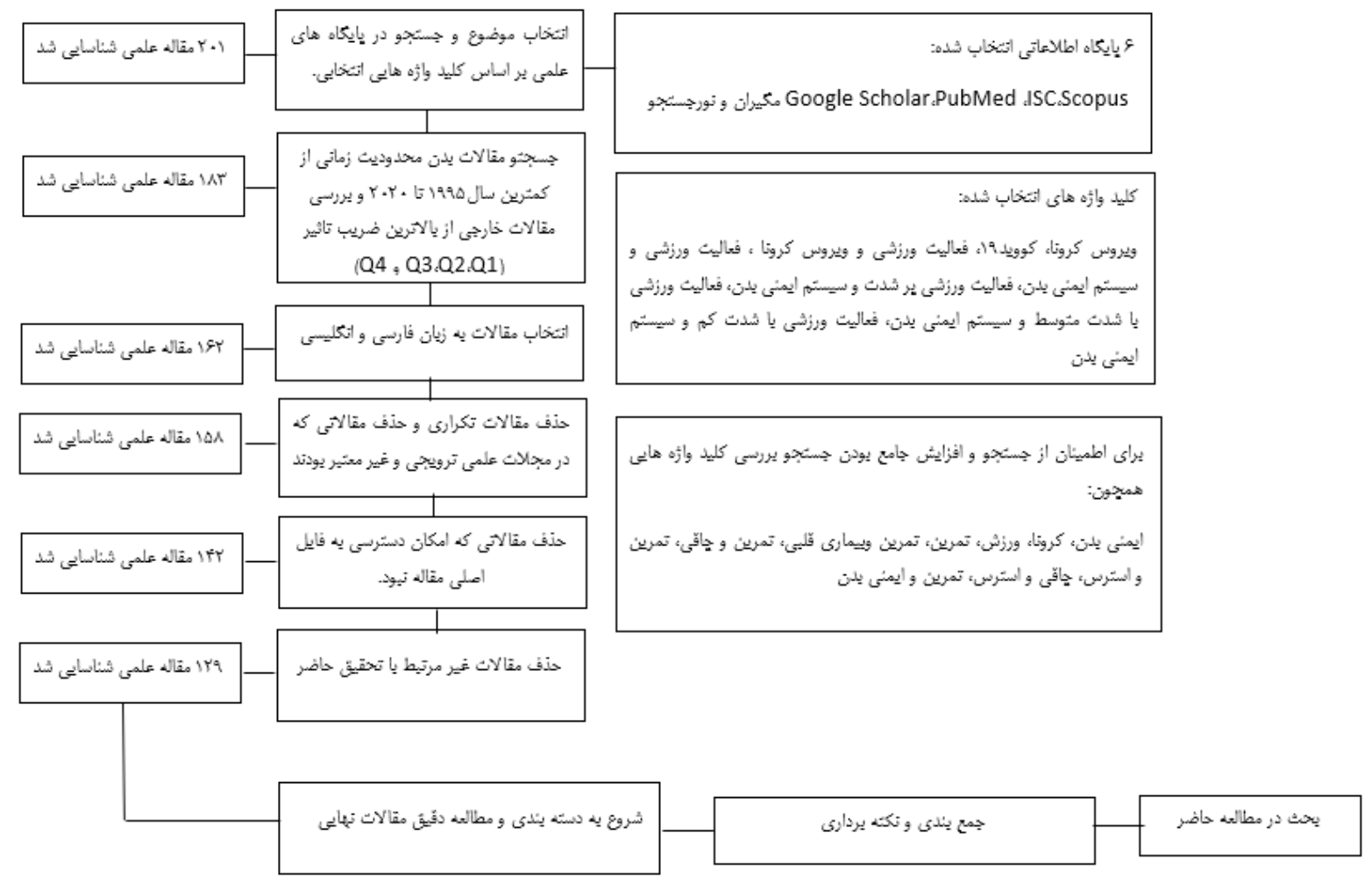

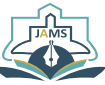

از طرفي محققين يك راهكار مؤثر يعنى انجام فعاليت ورزشى

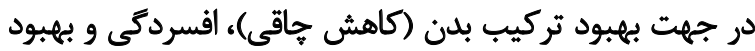

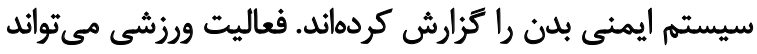
تغييرات فيزيولوزيكي ايجاد كند كه اين تغييرات فيزيولوزيكي ريكي

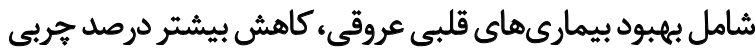

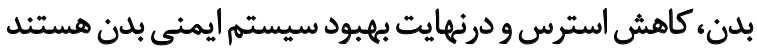

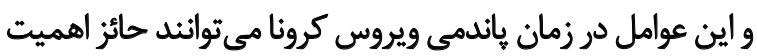

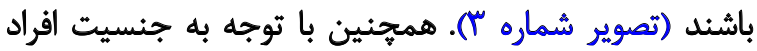

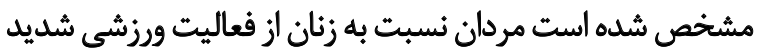

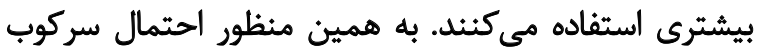

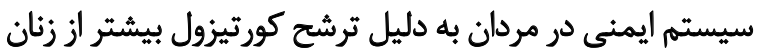

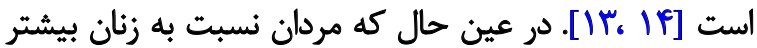

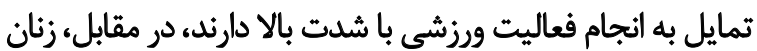

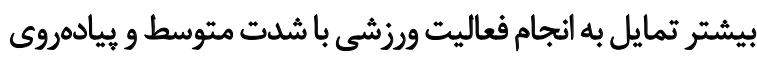

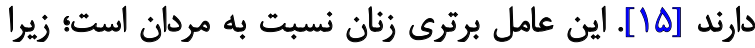

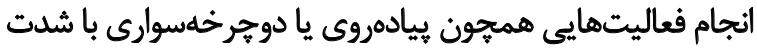

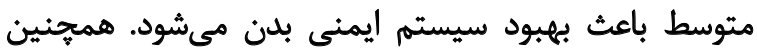

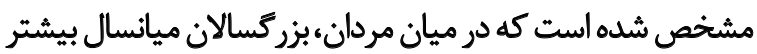

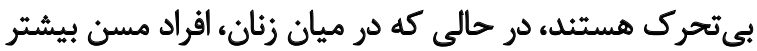

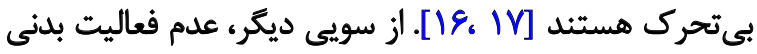

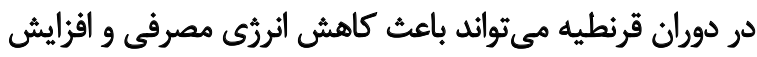

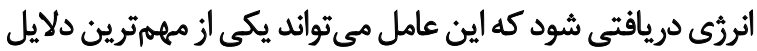

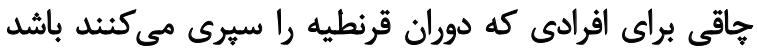

تصوير r. مراحل بررسي مقالات از ابتدا تا انتها مراحل بررسي مقالات در تصوير شماره ب نشان داده شده است.

ladits

\section{4 كوئ 19} شيوع ويروس كرونا باعث شد بيشتر كشورهاي جهان اقدامي

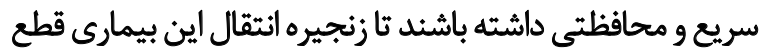

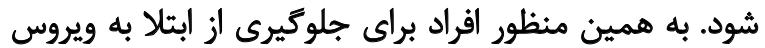

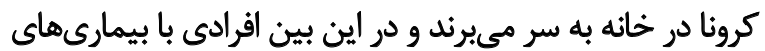

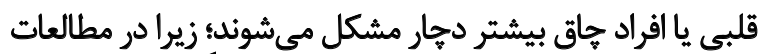

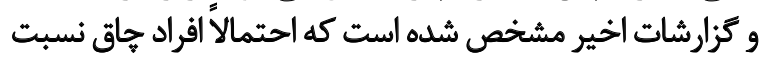

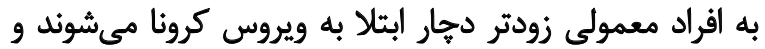

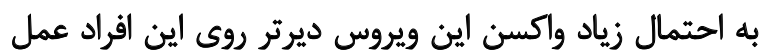

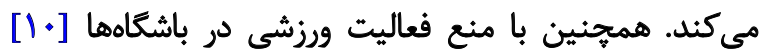

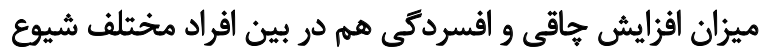

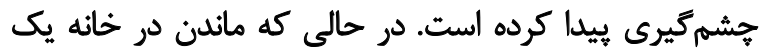

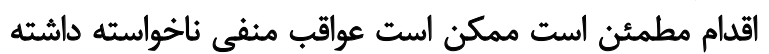

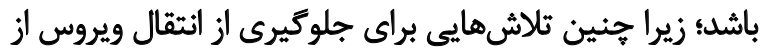

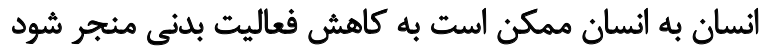

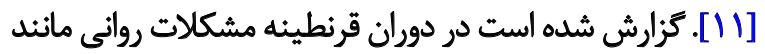

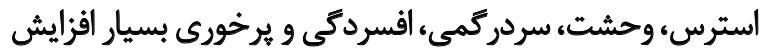

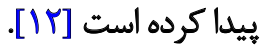


مختصرى در ارتباط با اين تغييرات فيزيولوريكى خواهيم داشت.

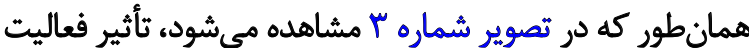

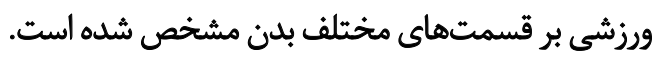

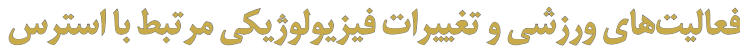

مشخص شده است كه با افزايش شيوع ويروس كرونا و ماندن

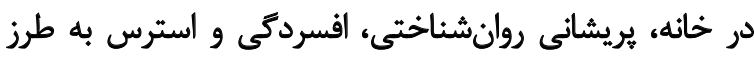

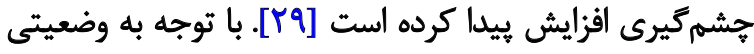

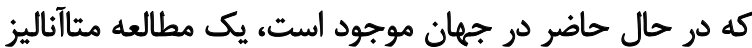

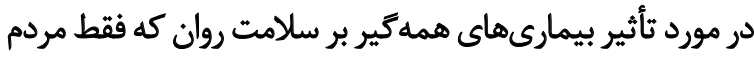

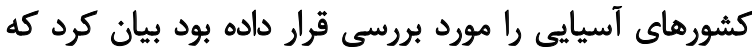

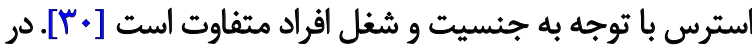

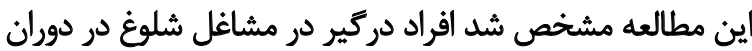

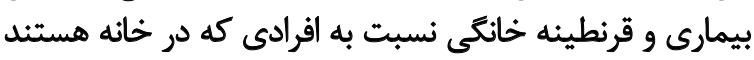

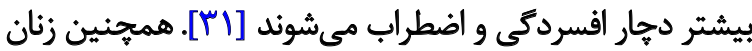

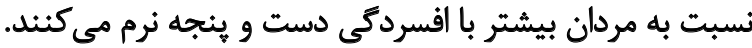

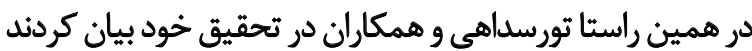

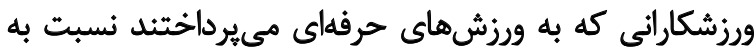

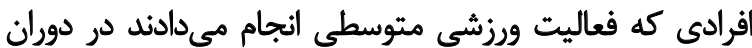

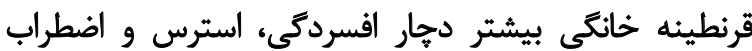

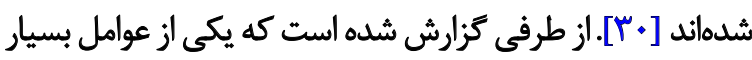

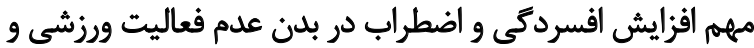

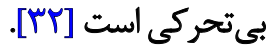

در اين بين، يكى از عواملى كه مي تواند باعث كاهش استرس

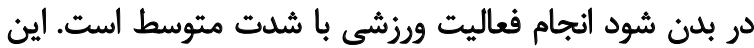

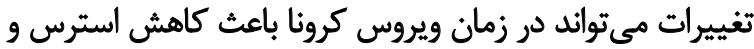

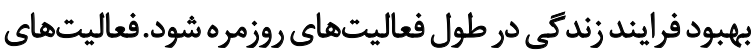

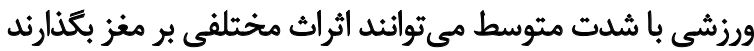

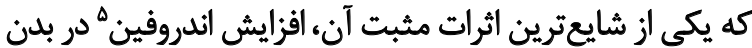

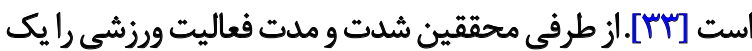

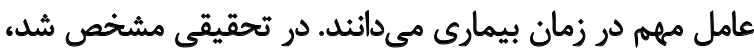

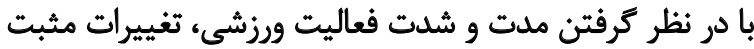

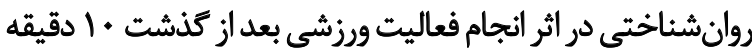

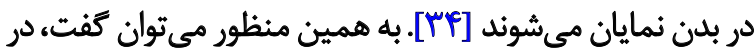

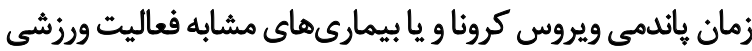
مى تواند يك عامل مههم و مؤثر باشد.

با توجه به اينكه فعاليت ورزشى خود باعث افزايش استرس در

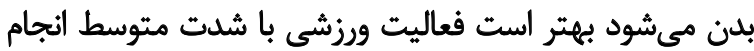

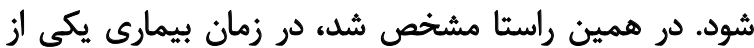

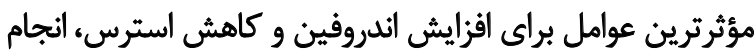

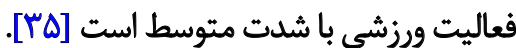

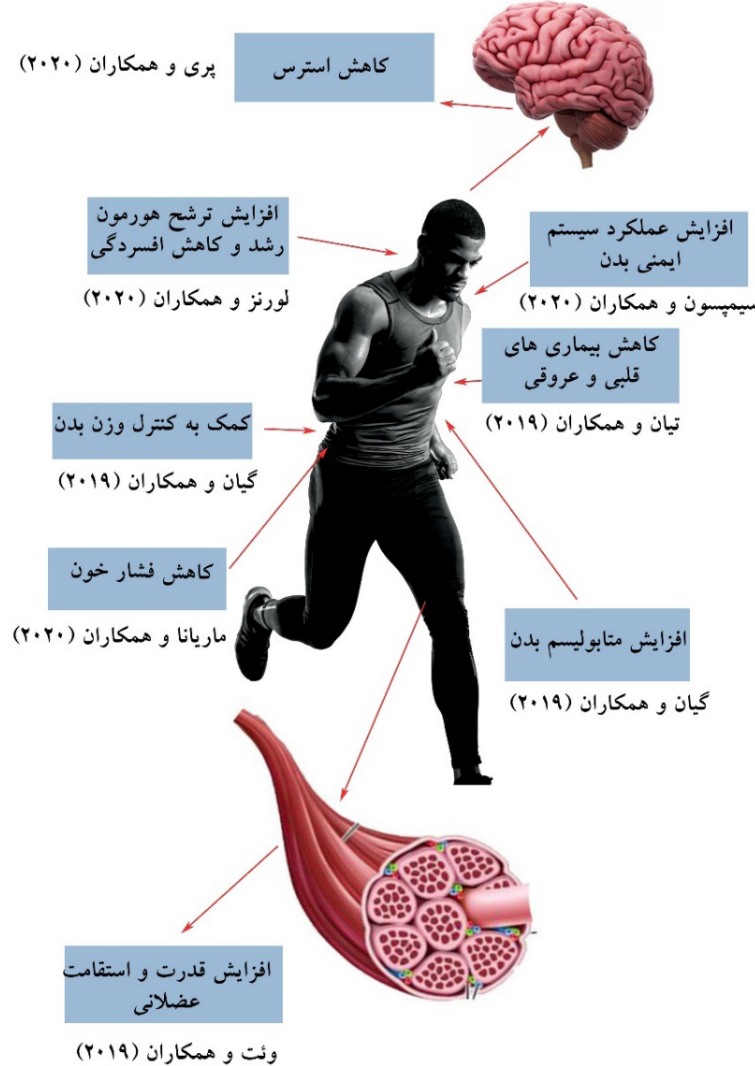

(4)

تصوير س. نماي كلى از تغييرات فيزيولوزيكى بدن به دنبال انجام فعاليتهاى

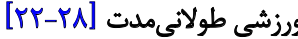

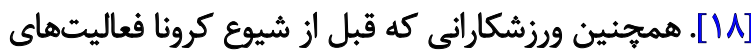

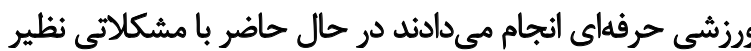

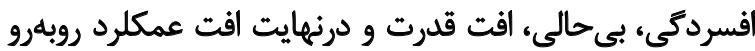

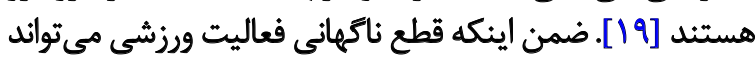

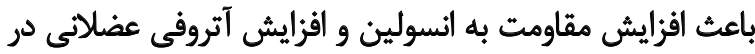

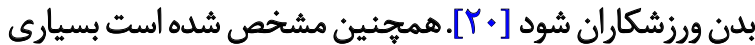

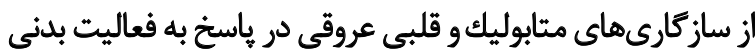

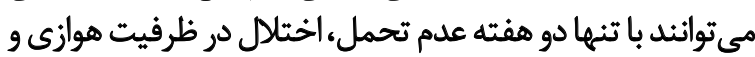

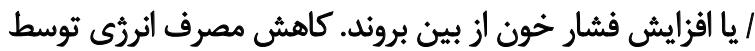

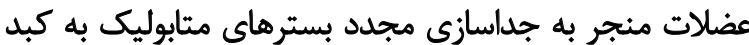

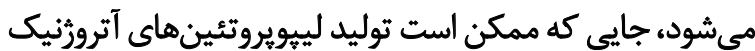

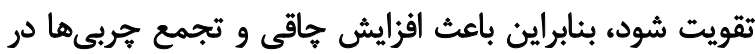

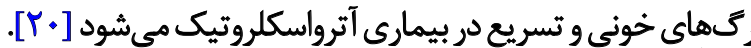

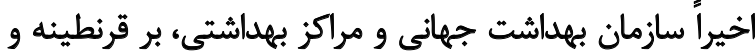

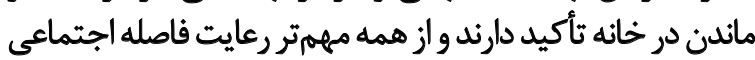

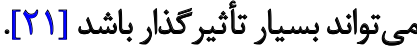

درنهايت به صورت كلى مىتوان كفت فعاليت ورزشي يك

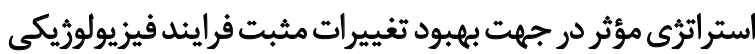

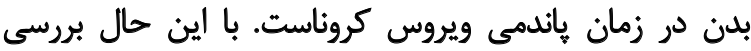


جدول ا. مدل بيشنهادى فعاليت ورزشى براى جلوكيرى از استرس [F]

\begin{tabular}{|c|c|c|c|c|}
\hline نوع قعاليت & مدتزمان فعاليت & ش شدت فعاليت & تعد|د فعاليت در هفته & كروه سنى \\
\hline بازى فعال & •r دقيقه & كم & هـ روز & 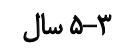 \\
\hline بازي طاب زئني، & 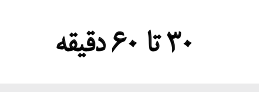 & كم ثا متونسط & حداقل سله روز در هفته & IV-8 سال IV \\
\hline دوجرخهنيادوارىى & حداقل •10 دقيقه در هُتْه & هتونسط & سه روز در هفته & 11 11 - \\
\hline تمرينات مقاومتى & • باتا .ع دقيقه & 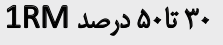 & حداقل يك روز در هفته & \\
\hline يبياندورى & 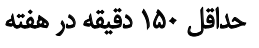 & كم ثا هتونسط & دو تا سه روز در هفته & $\angle 90$ \\
\hline
\end{tabular}

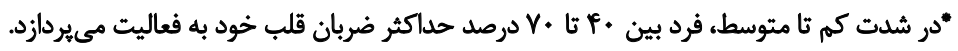

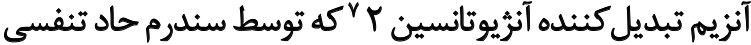

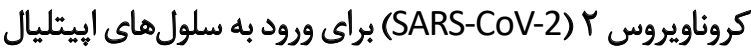

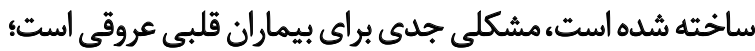

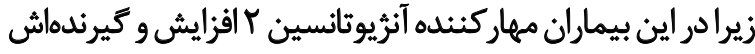

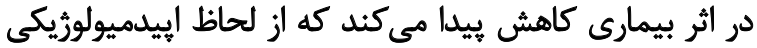

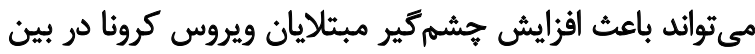

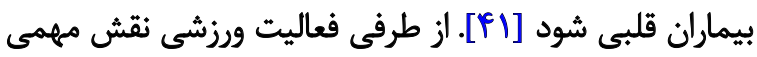

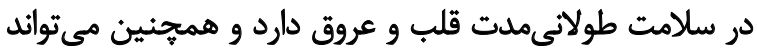

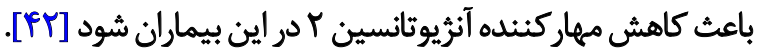

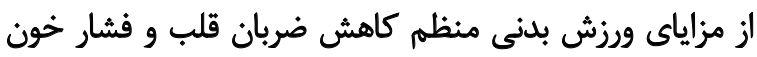

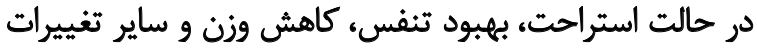

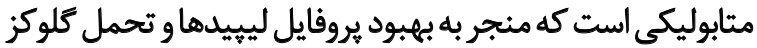

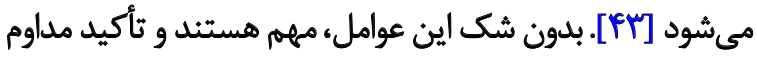

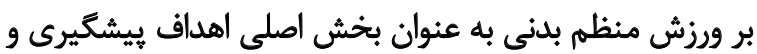
درمان را توجيه مى كنيند (تصوير شماره مf).

سازمان بهداشت جهانى دستورالعملهاى روشنى در مورد

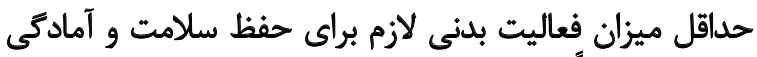

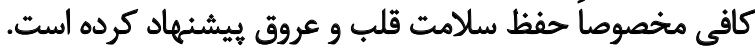

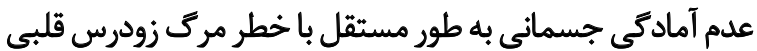

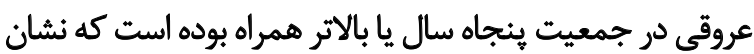

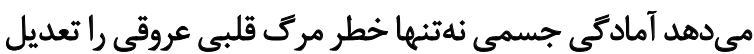

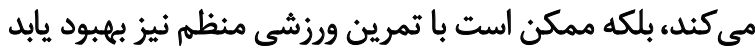

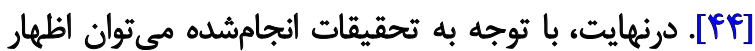

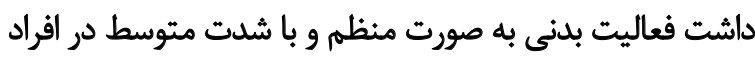

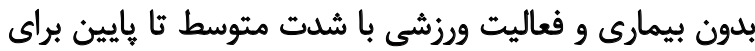

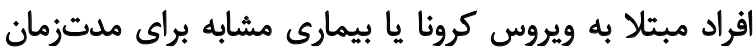

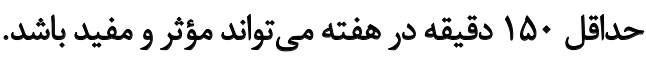

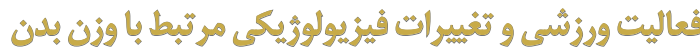

با قرنطينه خانكى (عدم فعاليت بدنى) و زياد شدن كالرى

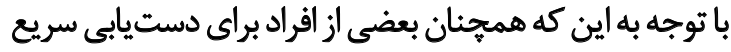

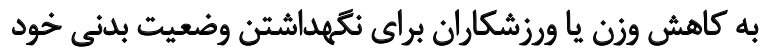

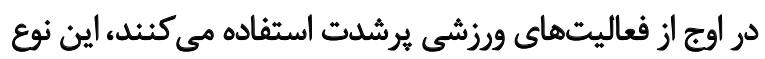

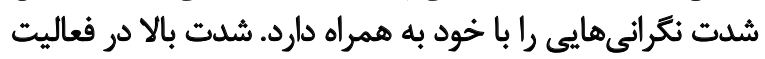

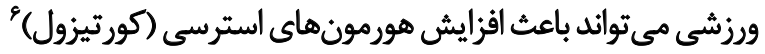

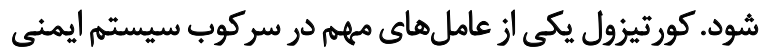

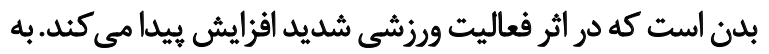

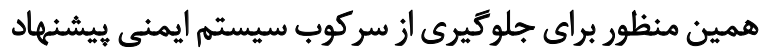

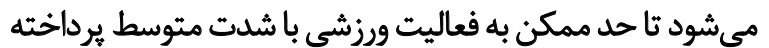

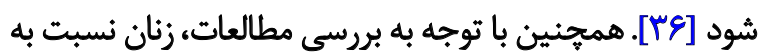

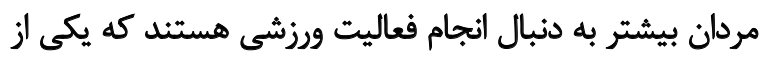

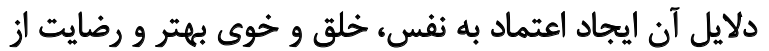

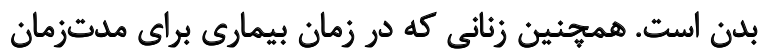

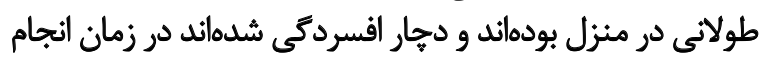

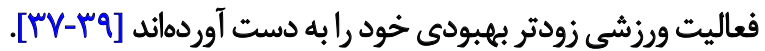

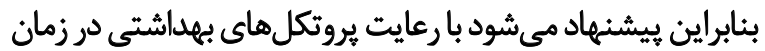

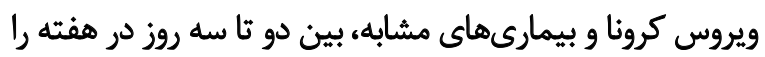

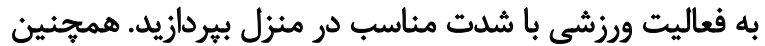

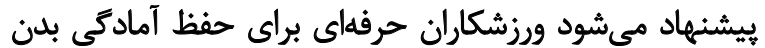

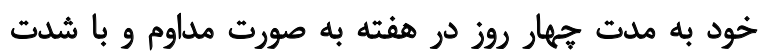

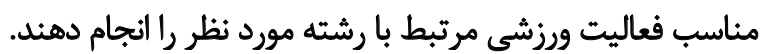

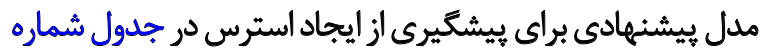

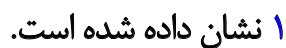

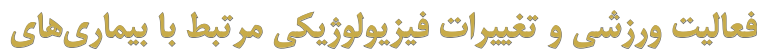

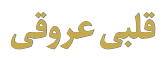

دادههاى إيبدميولوزيكى اوليه نشان مىدهند كه افرادى كه

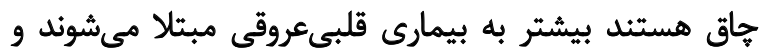

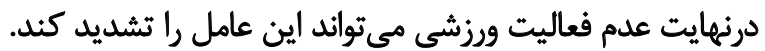




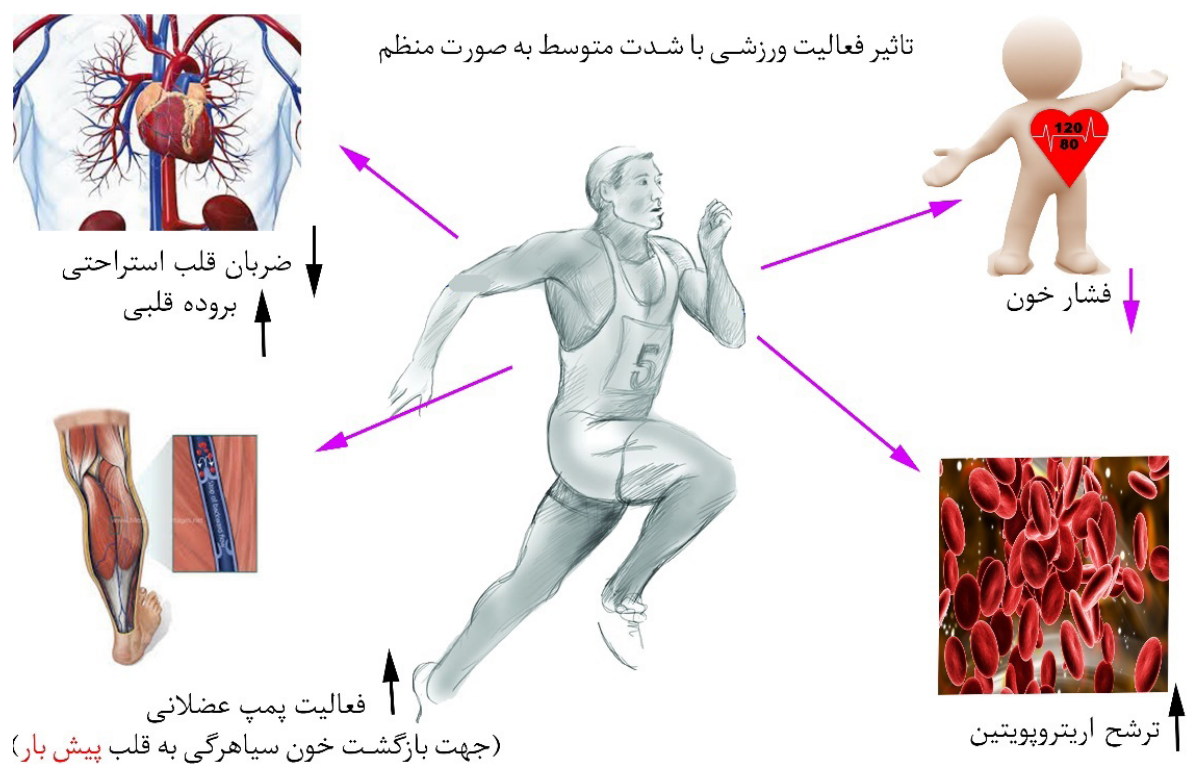

\section{(c)}

انجام فعاليت ورزشى مي تواند يكى از مههمترين عوامل جلوكيرى از ابتلا به اين ويروس و بيمارىهايت مشابه باشيد.

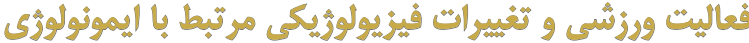

مطالعات متعددى در خصوص اين ويروس انجام شدهاند، اما

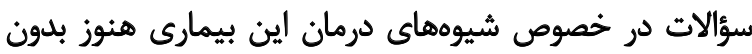

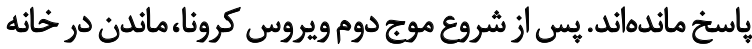

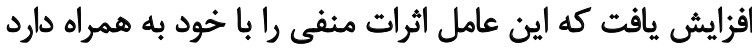

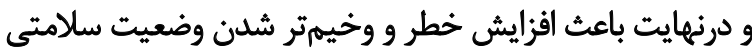

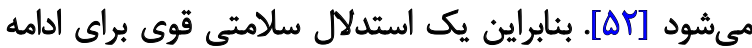

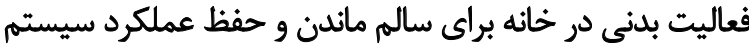

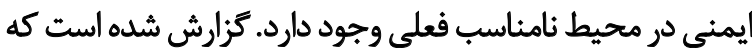

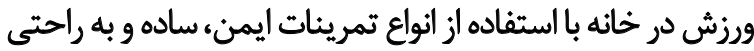

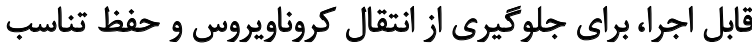

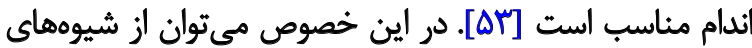

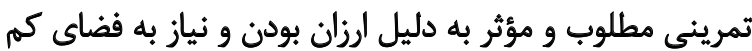

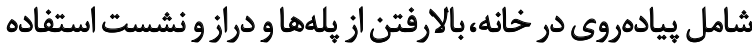

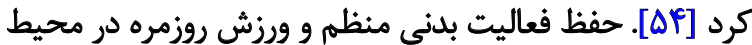

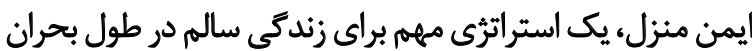

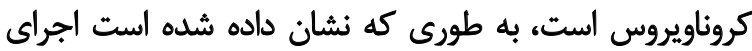

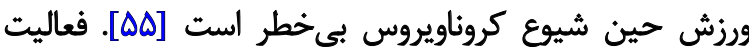

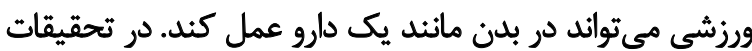

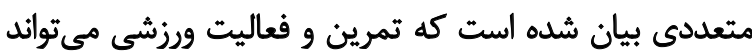

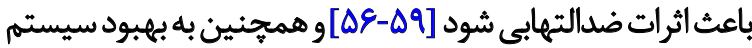

[DF] تصوير F. تأثير فعاليت ورزشى با شدت متوسط بر شاخصهاى قلبي عروقى

دريافتى، افزايش وزن با سرعت زيادى افزايش بيدا كرده است.

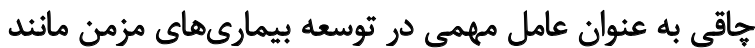

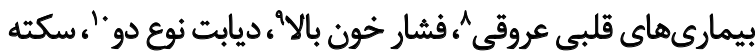

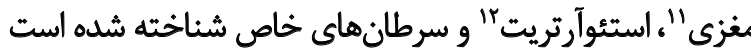

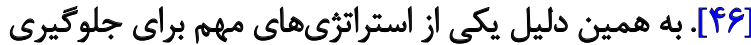

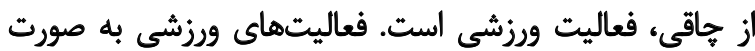

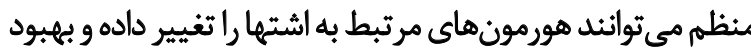

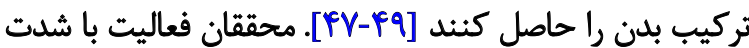

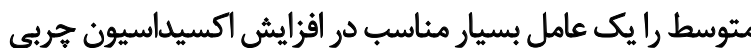

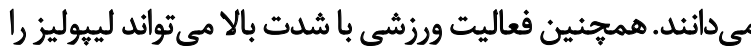

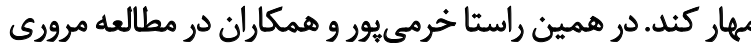

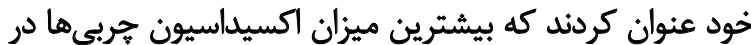

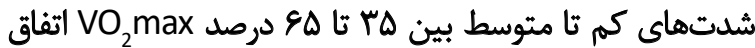

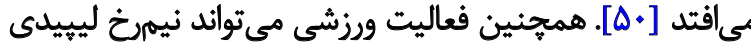

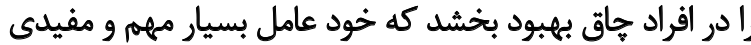

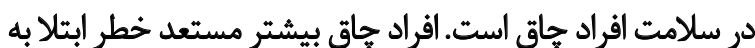

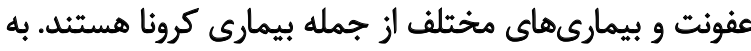

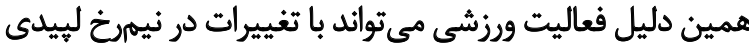

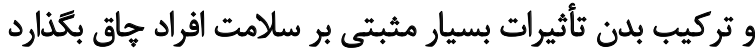

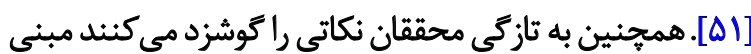

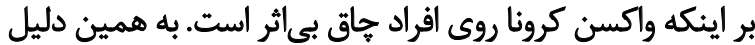

8. Cardiovascular disease

9. High blood pressure

10. Type 2 diabetes

11. Stroke

12. Osteoarthritis 


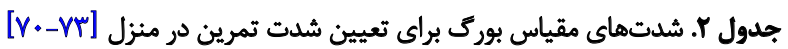

\begin{tabular}{|c|c|c|c|c|c|c|}
\hline 1. & $\checkmark$ & $\bullet$ & $r$ & $r$ & صفر & شُماره \\
\hline تمرين خيلى سخت & تمرين بسيار سخت & تمرين سخت & تمرين با شدت متوسط & تمرين آسان & فرد در حالت استراحت & فُشار تمرين \\
\hline
\end{tabular}

اذعان شده است كه ورزش منظم و متعادل، ايمنى ضدباكترى

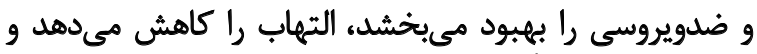

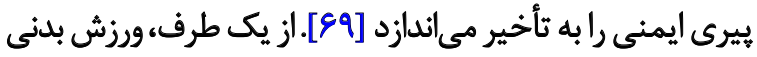

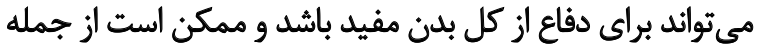

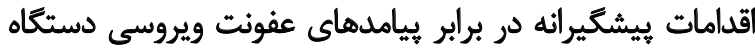

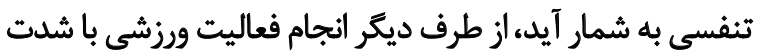

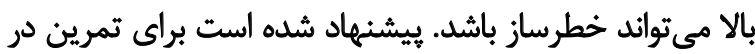

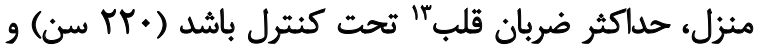

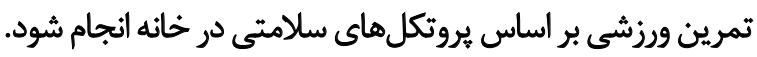

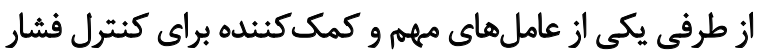

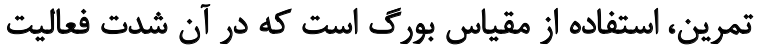

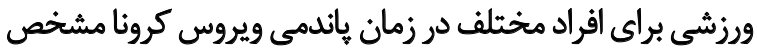

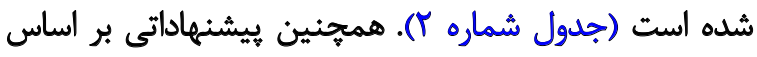

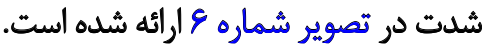

As

در واقع ويروس كرونا با علاثمي كه با خود به همراه دارد به مردم

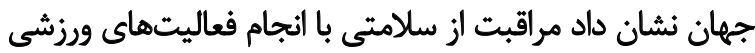

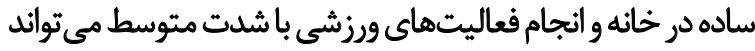

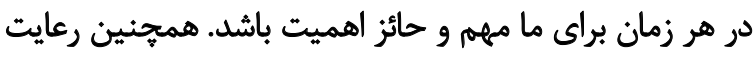

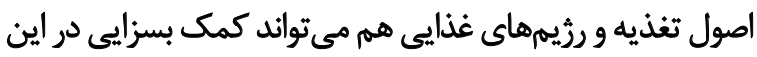

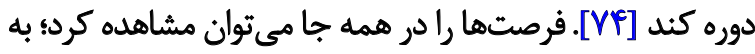
عنوان مثال انجام حركات كششى در خانه يا انجام تمرينات يونا

13. Maximum Heart Rate

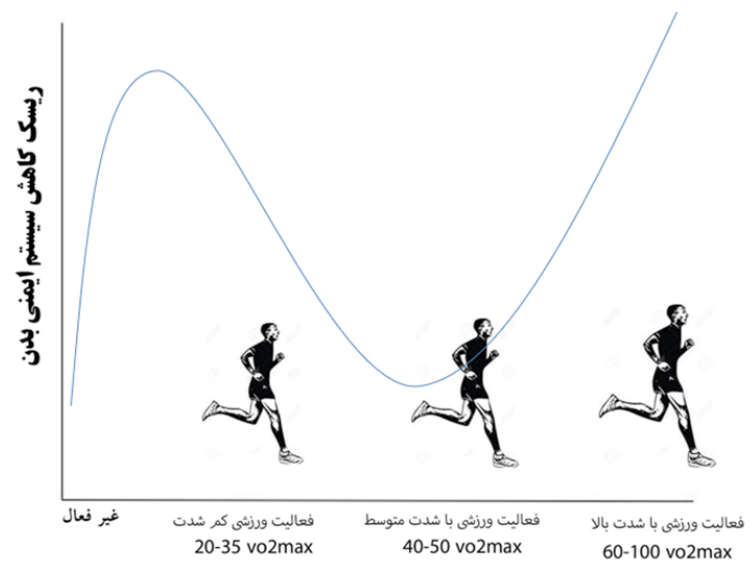

تصوير ه. تغييرات سيستم ايمنى بدن در فعاليتهاى ورزشى متفاوت (j)
ايمنى كمك كند و سلولهاى T را در بدن افزايش دهد [هـ].

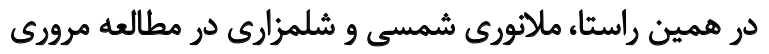

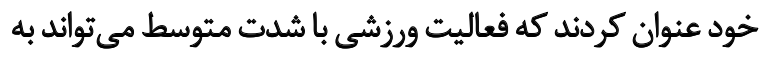

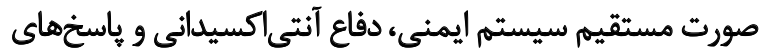

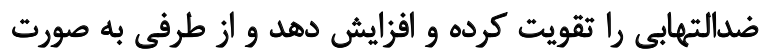
غيرمستقيهم مشكلات مربوط به اضطراب و حساسيت انسوليني

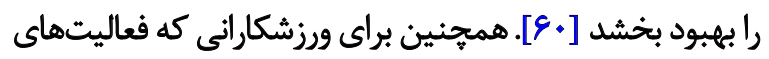

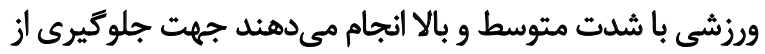

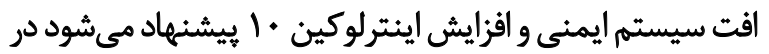

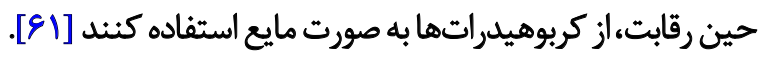

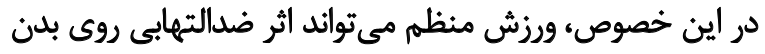

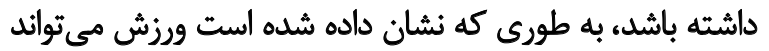

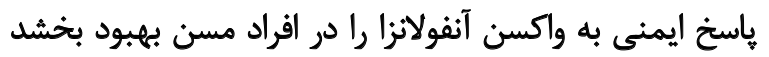

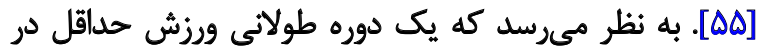

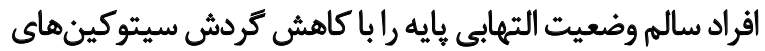

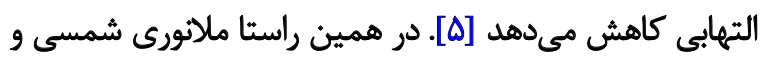

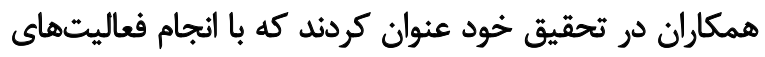

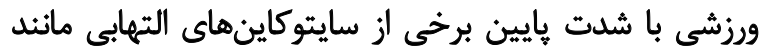

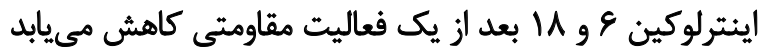

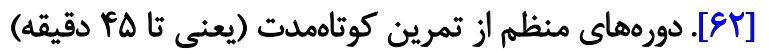

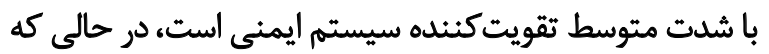

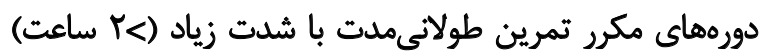

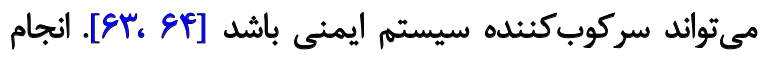

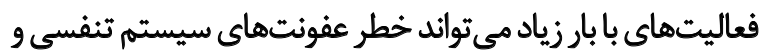

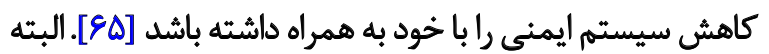

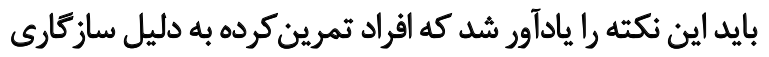

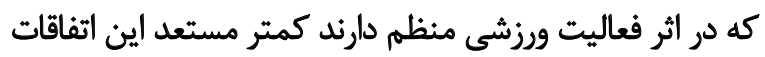

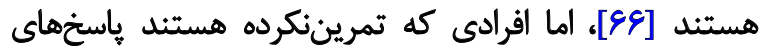
شديدترى به سيستم ايمني و سركوب آن در تمرينات برشديد

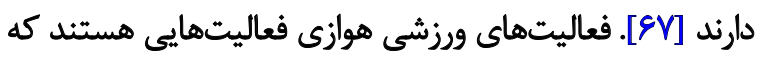

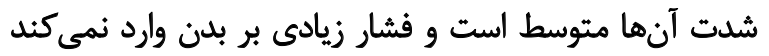

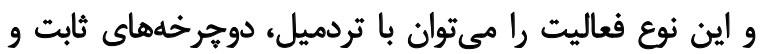

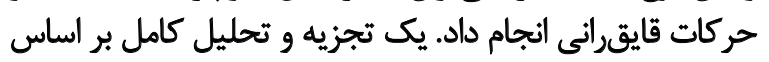

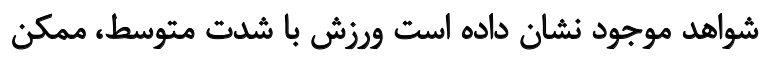

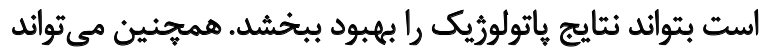

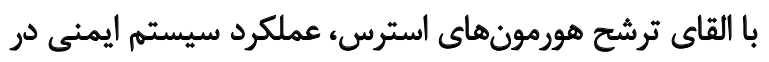

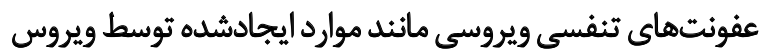

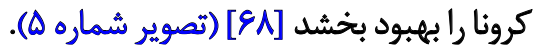




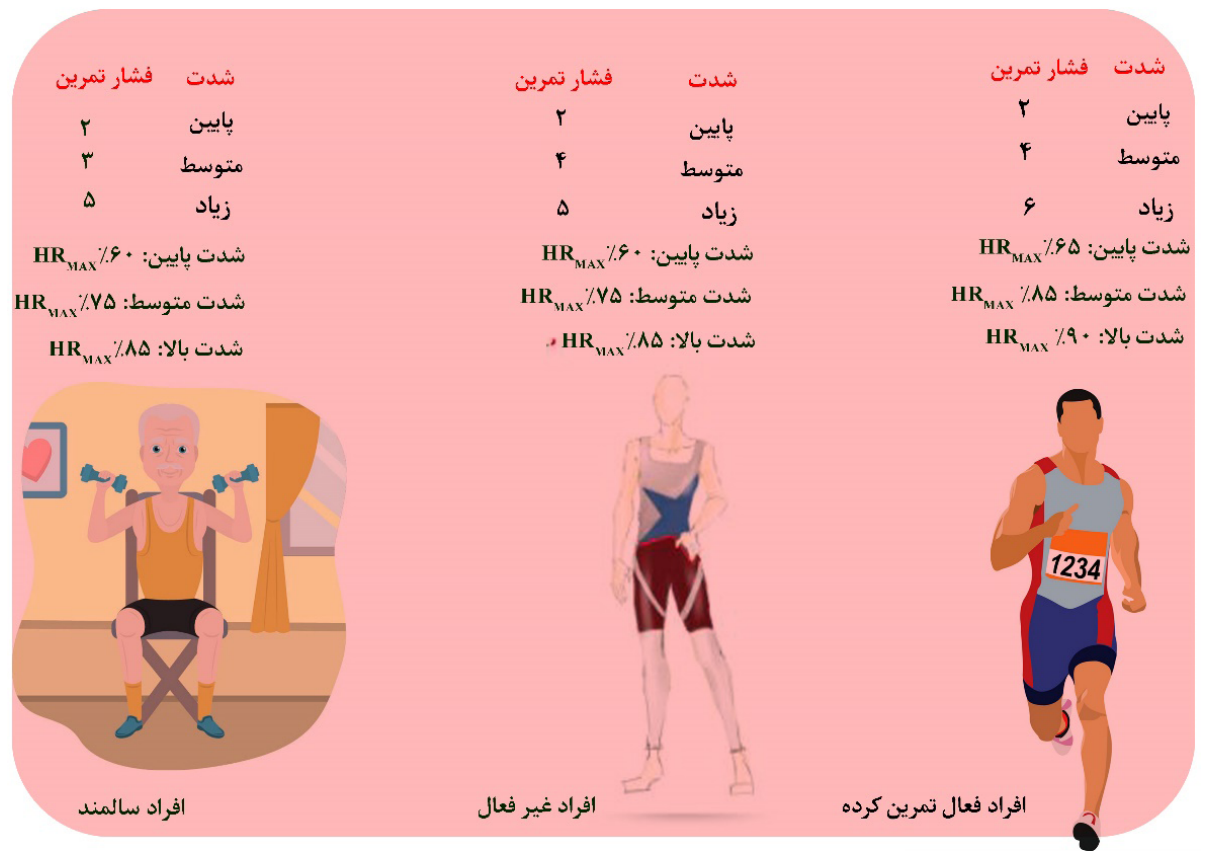

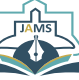

مشخص شد در افراد مسن ميزان مركىومير از طريق آنفولانزا در

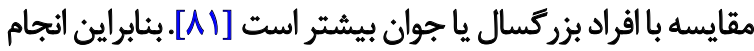

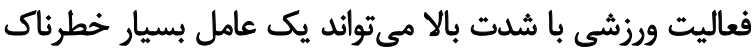

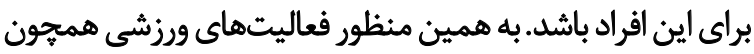

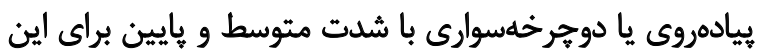

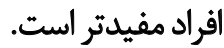

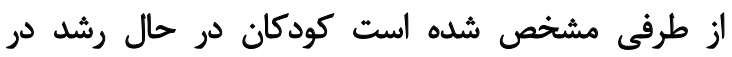

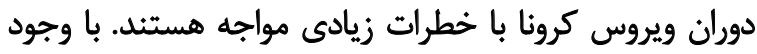

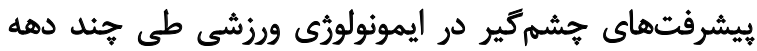

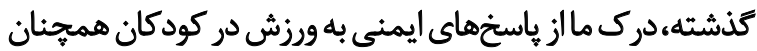

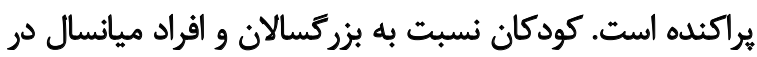

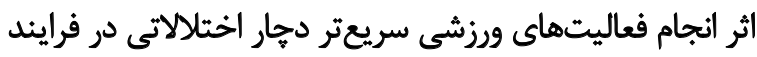

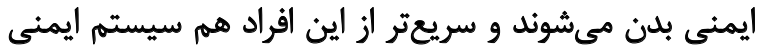

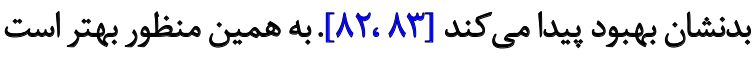

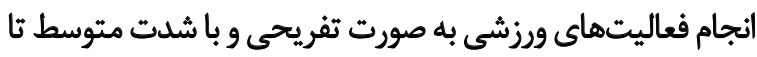

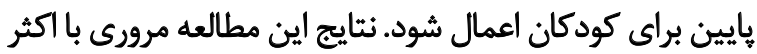

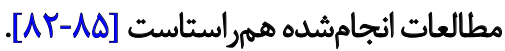

در عوض فعاليت بدنى براى كسانى كه مشكوك به به ويروس

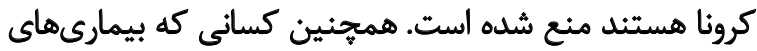

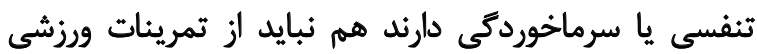

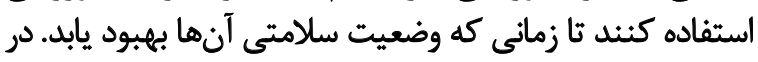

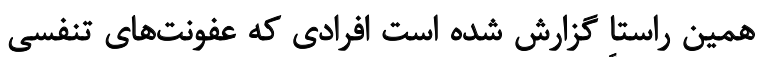

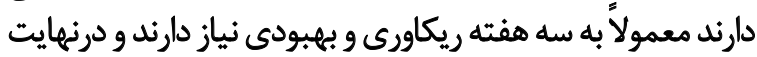

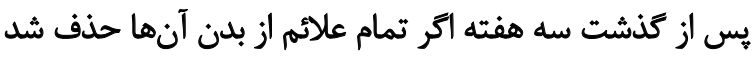

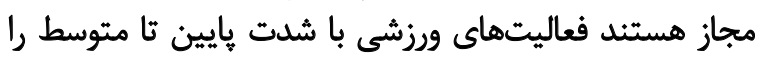

تصوير و. بيشنهادات جهت تعيين شدت و مدت فعاليت ورزشى

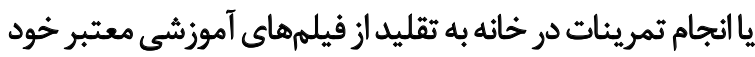

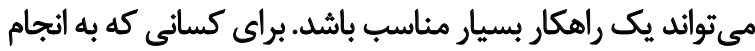

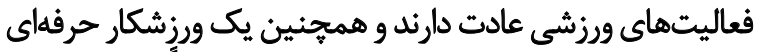

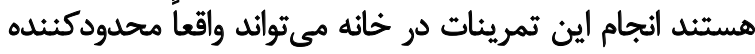

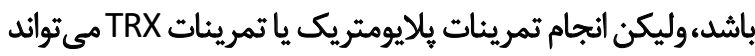

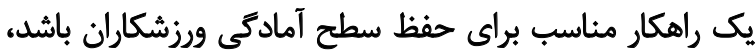

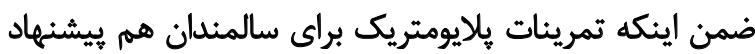

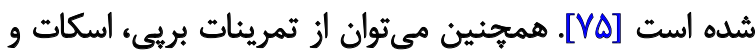

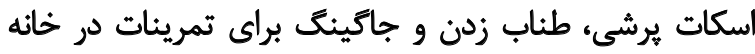

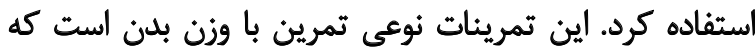

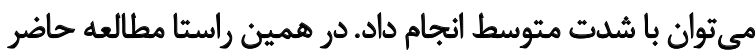

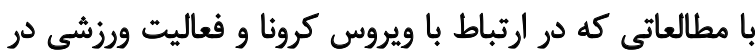

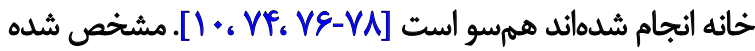

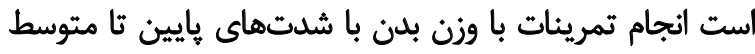

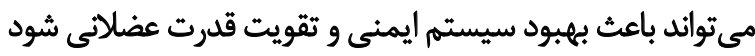

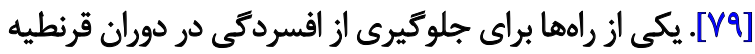

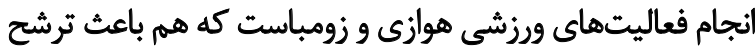

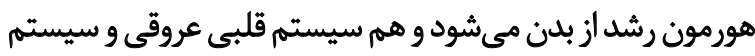

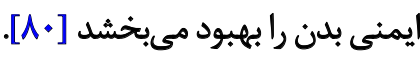

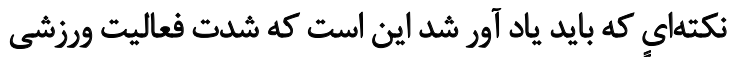

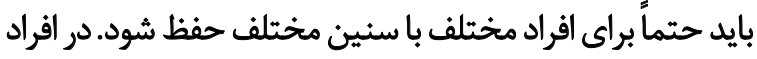

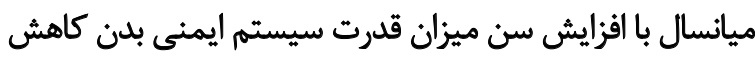

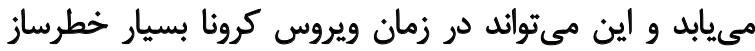

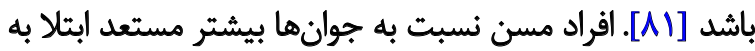

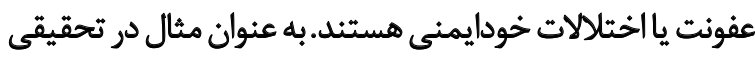


جدول r. مطالعات انجامشده در ارتباط با فعاليت ورزشى و سطح سيستم ايمنى بلن در جند سال اخير

\begin{tabular}{|c|c|c|c|c|c|}
\hline 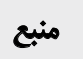 & تأثير بر سيستي اليمنى بدن & شدت فعاليت & نوع تمرين & 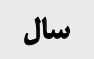 & نام محقق \\
\hline [१५] & 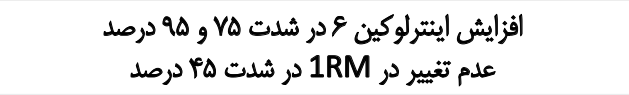 & $\begin{array}{l}\text { IRM g , VA r. PQ } \\
\text { 1RM }\end{array}$ & مقاومتى & $(r+r+)$ & رايثز و همكاران \\
\hline$[94]$ & 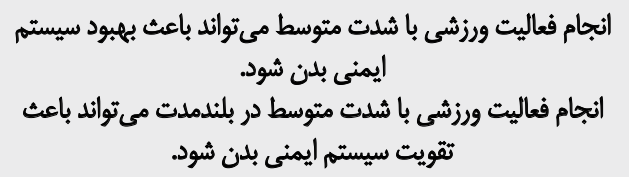 & متوت زياد & مقاومتى و هوازى تمرينات & $(r+Y \cdot)$ & مطانيهو و همكاران \\
\hline$[१ \diamond]$ & ايجاد اختلال در سيستم ايمنى بلن & شدت زياد & تمرينات هوازى & $\left(r+r_{0}\right)$ & 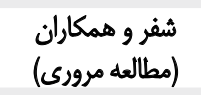 \\
\hline$[१ ६]$ & افزايش سطح سيستم ايمنى بلن & 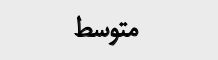 & تمرينات هوازى & $(r+r+)$ & (مطالعه مرورى) \\
\hline [9V] & افزايش سطح سيستم ايمنى بلن در شدت متوسط و كاهش موقت & تشدت زياد & تمرينات هوازى & $\left(r \cdot r_{0}\right)$ & هيكتون و همكاران \\
\hline$[9 \wedge]$ & افزايش سطح سيستم ايمنى بلن & شلت متوسط & تمرينات هوازى & $(Y \cdot Y \cdot)$ & سيتلينجر و همكاران \\
\hline [99] & 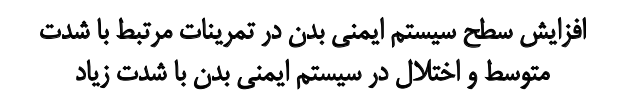 & شدت متوسط و زياد & 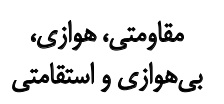 & $(r+19)$ & 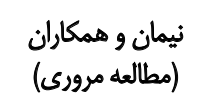 \\
\hline$[1 \cdots]$ & اختلالل در عملكرد سيستم ايمنى بلن & 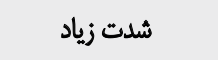 & 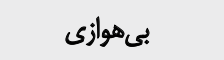 & $(r+\mid \Lambda)$ & دىسوزا و همكاران \\
\hline$[1.1]$ & 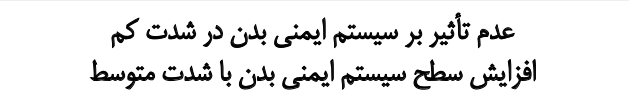 & شدت مثت كمر & هوازى & $(r+\mid N)$ & ملكي و همكاران \\
\hline$[1 \cdot r]$ & افزايش فعاليت سيستم ايمنى بلن & شلت زياد & بـ هوازى & $(Y+I V)$ & دورد و همكاران \\
\hline$[1 . \Psi]$ & 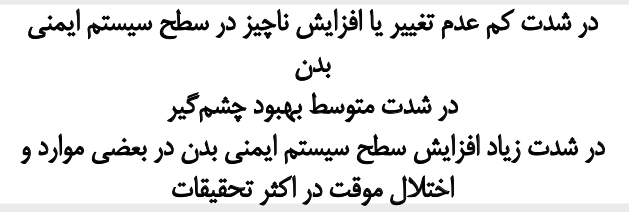 & با شدتهاى كم، زياد & فراليتهاي ورزشى تأثير تمام & $(Y \cdot 19)$ & (مطالعه ورورى) وهمكاران \\
\hline$[1 \cdot 4]$ & افزايش سطح سيسثم ايمنى بلن & شلت زياد & 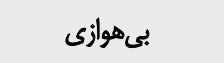 & $(r+1 \notin)$ & دورئلس و همكاران \\
\hline$[1 \cdot 0]$ & 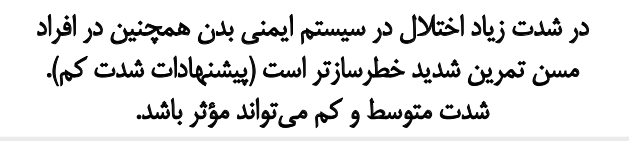 & شدت متدت زياد & تمرينات & $(r+18)$ & (مطالعز ورورى) همكاران \\
\hline$[1.9]$ & 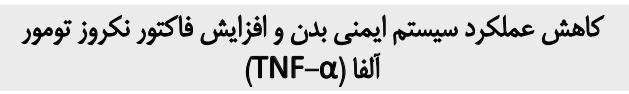 & شلفت زياد & 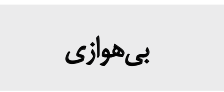 & $(r+10)$ & سرير و همكاران \\
\hline$[\mathrm{I} \cdot \mathrm{V}]$ & 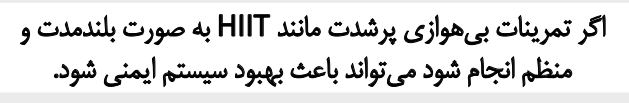 & ش ت ملت زياد & بي هوازى & $\left.(r+1)^{r}\right)$ & زوتسلوت و همكاران \\
\hline$[1 \cdot 1]$ & افزايش سطح سيستم ايمنى بلن & شلت مثوسط & 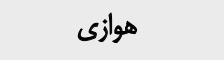 & $(Y \cdot I f)$ & غالامثرّاد و همكاران \\
\hline$[1.9]$ & كاهش يا افزايش سطح سيستم ايمنى بلن در شدت زياد & شدت زياد & بـ هوازى و هوازى & $(r+10)$ & 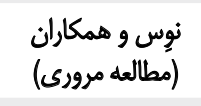 \\
\hline$[11 \cdot]$ & افزايش سطح سيستم ايمنى بلن & 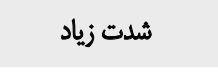 & 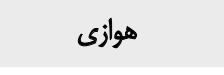 & $\left.(r+1)^{r}\right)$ & زيمر و همكاران \\
\hline [III] & انجام تمرينات بى هوازى با شدت زياد باعث اختلال در سيستم & تشلت زياد & بي هوازي & $\left(r \cdot r^{\prime}\right)$ & هايل و همكاران \\
\hline$[\mathrm{IIT}]$ & افزايش سطح سيستم ايمنى بلن & ش شدت متوسط & 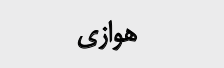 & $(r+1 r)$ & رحمتى و همكاران \\
\hline$[111]$ & 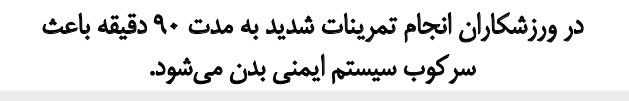 & 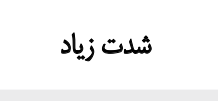 & بى بوازي & $(r \cdot I r)$ & شيروائى و همكاران \\
\hline$[11 \%]$ & افزايش سطح سيستم ايمنى بلن & شدت متوسط & 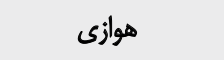 & $(Y \cdot I r)$ & ناوارو و همكاران \\
\hline
\end{tabular}




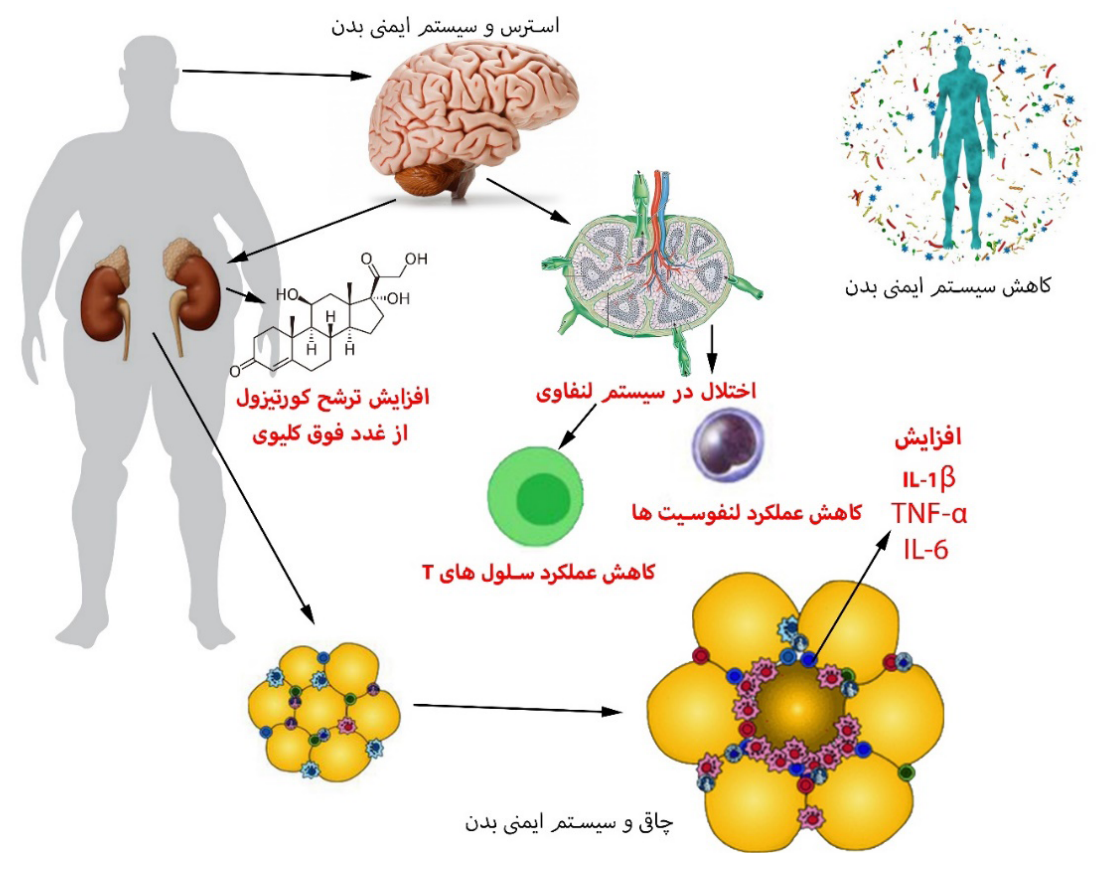

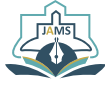

[9T]]. اما آنجه مشخص است اين است كه شدت بالاى فعاليت در

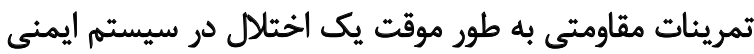

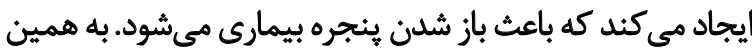

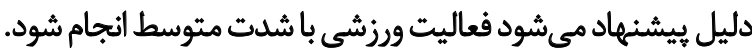

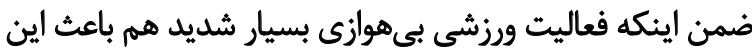

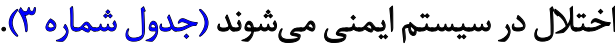
در مطالعه مرورى حاضر به بررسى ارتباط بين فعاليت ورزشى و

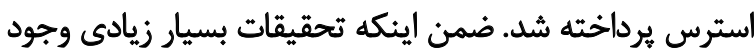

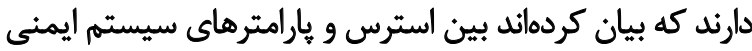

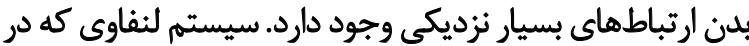

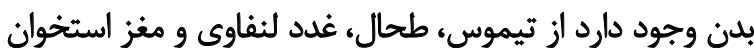

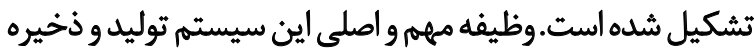

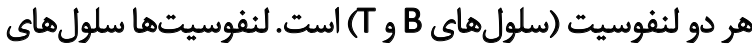

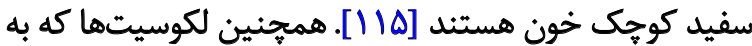

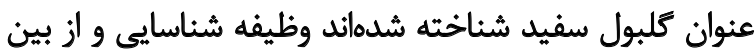

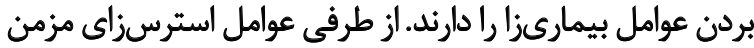

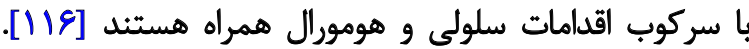

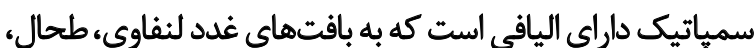

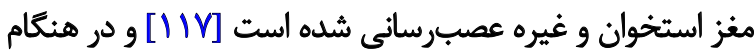

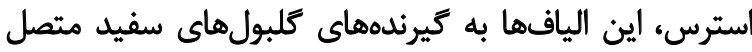
هستند و طيف كستردهاي از مواد را الرسال مي كئند كه دئن درنهايت

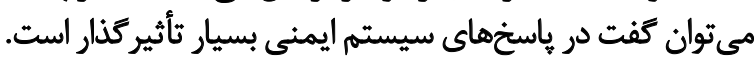

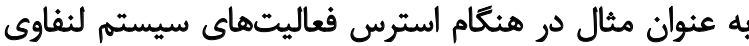

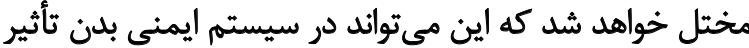

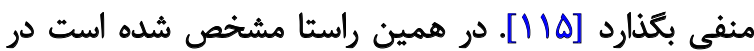

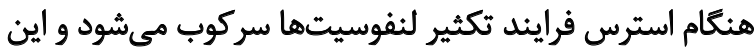

تصوير Y.ارتباط بين استرس و جاقى با سيستم ايمنى بدن

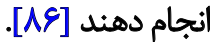
انجام فعاليتهاى ورزشى در دوران قرنطينه دقيقاً بايد مانند

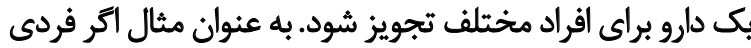

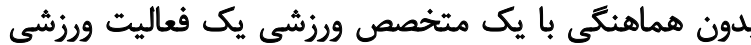

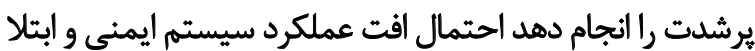

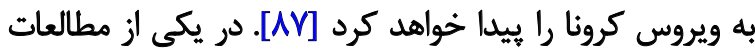

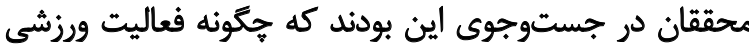

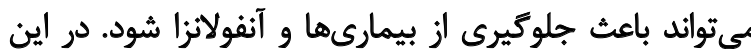

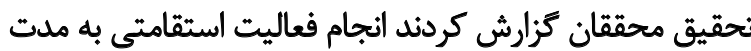

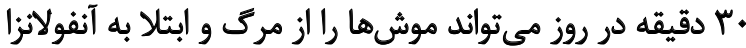

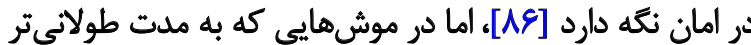

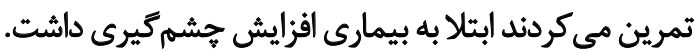
ضمن اينكه نوع فعاليتى كه در اين دوره انجام مىشود هم حائز

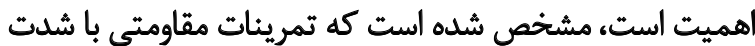

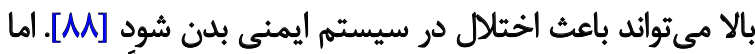

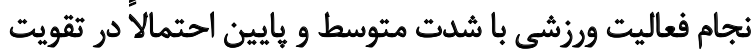

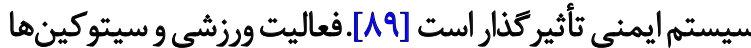

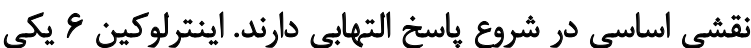

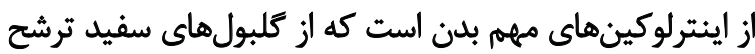

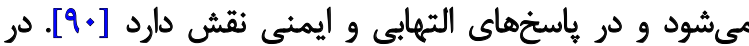

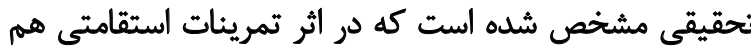

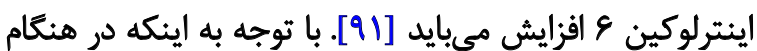

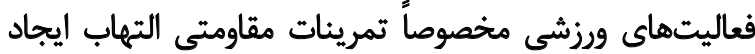

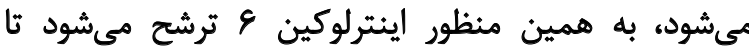

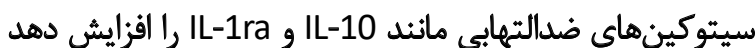




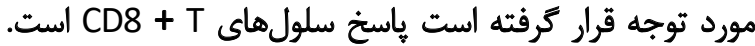

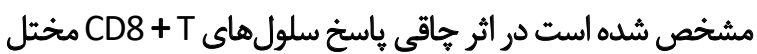

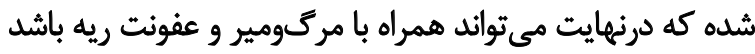

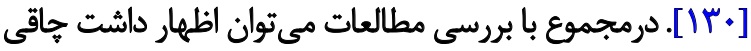

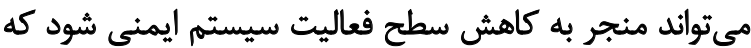
اين عامل در زمان ويروس كرونا خطرساز است (تصوير شماره V).

\section{نتيجهُكَيرى}

با توجه به شيوع ويروس كرونا و افزايش ماندن در خانه، انجام

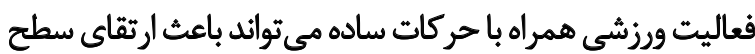

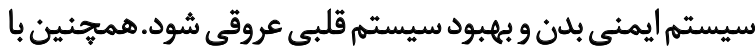

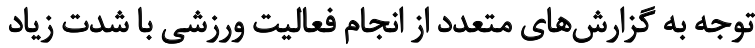

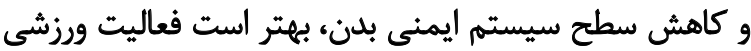

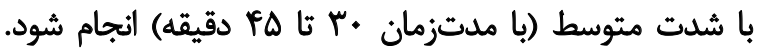

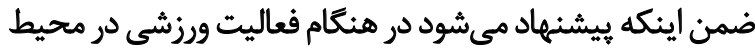

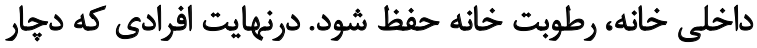

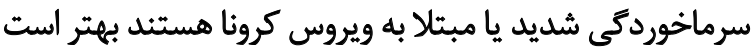
از فعاليت ورزشى تا بهبودى كامل خوددارى كنئد.

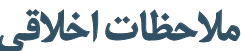

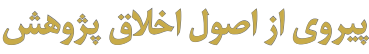

اصول اخلاقى در نكارش مقاله، طبق دستورالعمل كميته ملى اخلاق و آيين نامه COPE رعايت شده است مقاله

$$
\text { ollo }
$$

معاونت يُؤهشى و فناورى دانشكاه تربيت مدرس حامى مالى ئى اين ثرؤش بوده است.

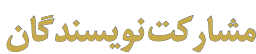

نويسندكان معيارهاى كميته بينالمللى سردبيران نشريات يزشكى (ICMJE) را رعايت كرداندان يندان.

\section{تعارض منأقع}

بنابر اظهار نويسندكان اين مقاله تعارض منافع ندارد.

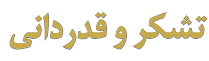

نويسندكان مقاله تشكر و قدردانى خود را از معاونت يثروهشى و فناورى دانشكاه تربيتمدرس ابراز ميكر وقداني خدارند.
يكى از عاملهاي مهم در ارتباط با استرس و سيستم ايمنى

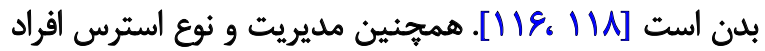

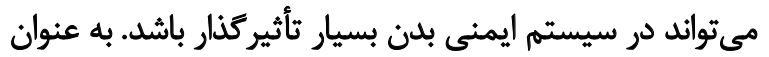

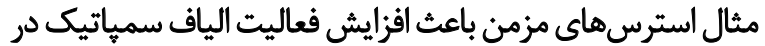

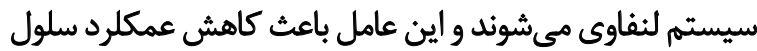

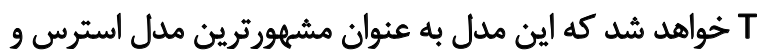

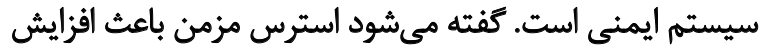

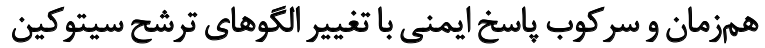

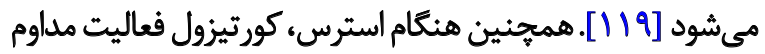

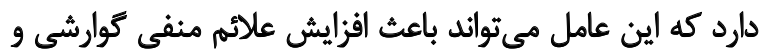

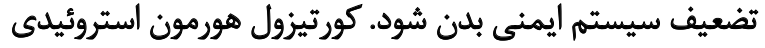

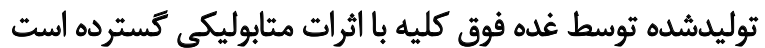

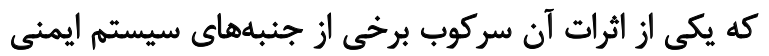

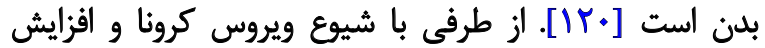

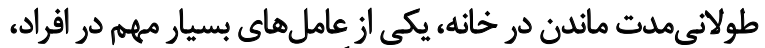

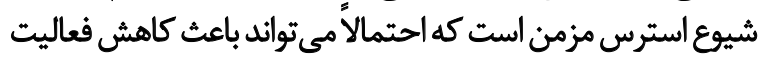

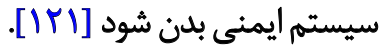

جاقى عملكرد ايمنى بدن را مختل مي كند، تعداد لكوسيتها

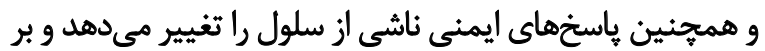

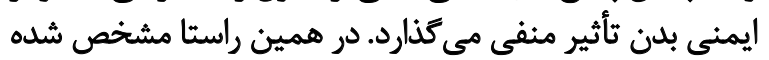

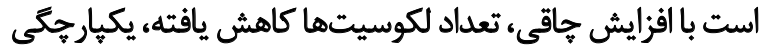

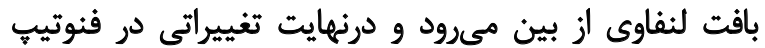

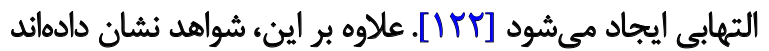

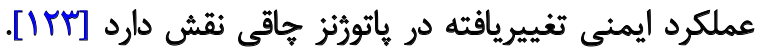

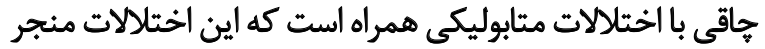

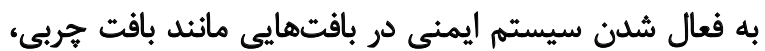

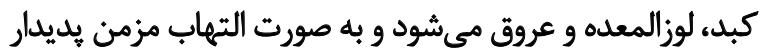

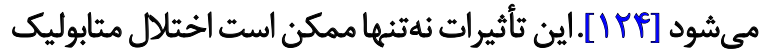

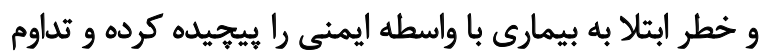

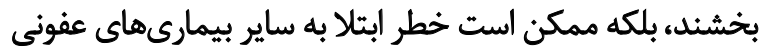

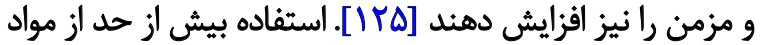

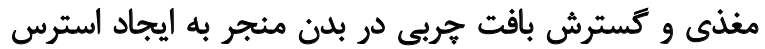

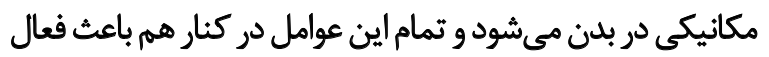

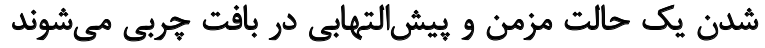

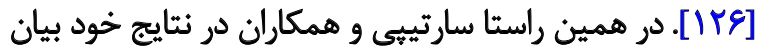

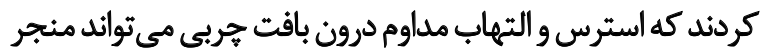

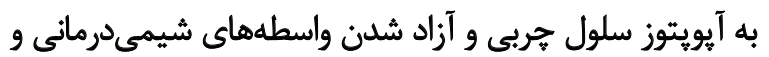

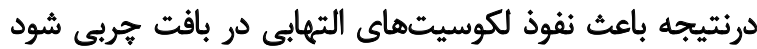

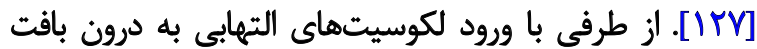

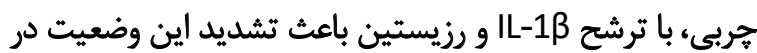

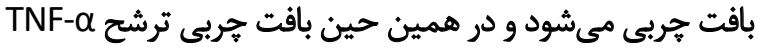

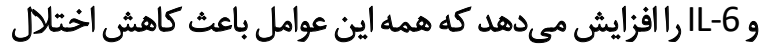

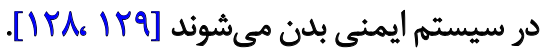
همجنين از عواملى كه در ارتباط با جاقى و سيستم ايمنى بدن 


\section{References}

[1] World Health Organization. Laboratory testing of human suspected cases of novel coronavirus (nCoV) infection: Interim guidance [Internet]. 2020 [Updated 2020 January 10]. Available from: https://apps.who. int/iris/handle/10665/330374

[2] Guan WJ, Ni ZY, Hu Y, Liang WH, Ou CQ, He JX, et al. Clinical characteristics of coronavirus disease 2019 in China. N Engl J Med. 2020; 382(18):1708-20. [DOI:10.1056/nejmoa2002032]

[3] Zheng J. SARS-CoV-2: An emerging coronavirus that causes a global threat. Int J Biol Sci. 2020; 16(10):1678-85. [DOI:10.7150/ijbs.45053] $[\mathrm{PMCID}]$

[4] Nikpouraghdam M, Jalali Farahani A, Alishiri G, Heydari S, Ebrahimnia $M$, Samadinia $H$, et al. Epidemiological characteristics of coronavirus disease 2019 (COVID-19) patients in IRAN: A single center study. J Clin Virol. 2020; 127:104378. [DOI:10.1016/j.jcv.2020.104378]

[5] Takian A, Raoofi A, Kazempour-Ardebili S. COVID-19 battle during the toughest sanctions against Iran. Lancet. 2020; 395(10229):1035-6. [DOI:10.1016/S0140-6736(20)30668-1]

[6] World Health Organization. Coronavirus Disease (COVID-19) Dashboard [Internet]. 2020 [Updated 2021 May 15]. Available from: https://covid19.who.int/

[7] Li G, Fan Y, Lai Y, Han T, Li Z, Zhou P, et al. Coronavirus infections and immune responses. J Med Virol. 2020; 92(4):424-32. [DOI:10.1002/ jmv.25685]

[8] Shamsi MM, Hassan ZM, Gharakhanlou R. Exercise-induced chaperokine activity of hsp70: Possible role in chronic diseases. In: Asea AAA, Kaur P, editors. Chaperokine Activity of Heat Shock Proteins. Germany: Springer; 2019. https://link.springer.com/chapter/10.1007/978-3-030-02254-9_10

[9] Woods JA, Hutchinson NT, Powers SK, Roberts WO, Gomez-Cabrera MC, Radak Z, et al. The COVID-19 pandemic and physical activity. Sports Med Health Sci. 2020; 2(2):55-64. [DOI: 10.1016/j.smhs.2020.05.006]

[10] Hammami A, Harrabi B, Mohr M, Krustrup P. Physical activity and coronavirus disease 2019 (COVID-19): Specific recommendations for homebased physical training. Manag Sport Leis. 2020:1-6. [DOI:10.1080/237 50472.2020.1757494]

[11] Chen P, Mao L, Nassis GP, Harmer P, Ainsworth BE, Li F. Coronavirus disease (COVID-19): The need to maintain regular physical activity while taking precautions. J Sport Health Sci. 2020; 9(2):103-4. [DOI:10.1016/ jjshs.2020.02.001] [PMCID]

[12] Brooks SK, Webster RK, Smith LE, Woodland L, Wessely S, Greenberg $\mathrm{N}$, et al. The psychological impact of quarantine and how to reduce it: Rapid review of the evidence. Lancet. 2020; 395(10227):912-20. [DOI:10.1016/S0140-6736(20)30460-8]

[13] Monteiro CA, Conde WL, Matsudo SM, Matsudo VR, Bonseñor IM, Lotufo PA. A descriptive epidemiology of leisure-time physical activity in Brazil, 1996-1997. Rev Panam Salud Publica. 2003; 14(4):246-54. [DOI:10.1590/s1020-49892003000900005]

[14] Burton NW, Turrell G. Occupation, hours worked, and leisure-time physical activity. Prev Med. 2000; 31(6):673-81. [DOI:10.1006/ pmed.2000.0763]

[15] Abel T, Graf N, Niemann S. Gender bias in the assessment of physical activity in population studies. Soz Praventivmed. 2001; 46(4):268-72. [DOI:10.1007/BF01593182]
[16] Martínez-González MA, Varo JJ, Santos JL, De Irala J, Gibney M Kearney J, et al. Prevalence of physical activity during leisure time in the European Union. Med Sci Sports Exerc. 2001; 33(7):1142-6. [DOI:10.1097/00005768-200107000-00011]

[17] Gomes VB, Siqueira KS, Sichieri R. [Physical activity in a probabilistic sample in the city of Rio de Janeiro]. Cad Saude Publica. 2001; 17(4):969 76. [DOI:10.1590/s0102-311x2001000400031]

[18] Booth FW, Roberts CK, Thyfault JP, Ruegsegger GN, Toedebusch RG. Role of inactivity in chronic diseases: Evolutionary insight and pathophysiological mechanisms. Physiol Rev. 2017; 97(4):1351-402. [DOI:10.1152/physrev.00019.2016]

[19] Sullivan M, Moore M, Blom LC, Slater G. Relationship between socia support and depressive symptoms in collegiate student athletes. J Study Sports Athlete Educ. 2020; 14(3):192-209. [DOI:10.1080/19357397.2 020.1768034

[20] Venkatasamy VV, Pericherla S, Manthuruthil S, Mishra S, Hanno R. Effect of physical activity on insulin resistance, inflammation and oxidative stress in diabetes mellitus. J Clin Diagn Res. 2013; 7(8):1764-6. [DOI:10.7860/JCDR/2013/6518.3306]

[21] Liu K, Zhou R, Wang B, Chen K, Shi LY, Zhu J-D, et al. Effect of green tea on glucose control and insulin sensitivity: A meta-analysis of 17 randomized controlled trials. Am J Clin Nutr. 2013; 98(2):340-8 [DOI:10.3945/ajcn.112.052746]

[22] Perry SA, Coetzer R, Saville CWN. The effectiveness of physical exercise as an intervention to reduce depressive symptoms following traumatic brain injury: A meta-analysis and systematic review. Neuropsychol Rehabil. 2020; 30(3):564-78. [DOI:10.1080/09602011.2018.1469417]

[23] Laurens C, Bergouignan A, Moro C. Exercise-released myokines in the control of energy metabolism. Front Physiol. 2020; 11:91. [DOI:10.3389/fphys.2020.00091]

[24] Simpson RJ, Campbell JP, Gleeson M, Krüger K, Nieman DC, Pyne DB, et al. Can exercise affect immune function to increase susceptibility to infection? Exerc Immunol Rev. 2020; 26:8-22. [PMID]

[25] Tian D, Meng J. Exercise for prevention and relief of cardiovascular disease: Prognoses, Mechanisms, and Approaches. Oxid Med Cell Longev. 2019; 2019:3756750. [DOI: 10.1155/2019/3756750]

[26] Emerenziani GP, Ferrari D, Marocco C, Greco EA, Migliaccio S, Lenzi A et al. Relationship between individual ventilatory threshold and maximal fat oxidation (MFO) over different obesity classes in women. PLoS One. 2019; 14(4):e0215307. [DOI:10.1371/journal.pone.0215307]

[27] Bersaoui M, Baldew S-SM, Cornelis N, Toelsie J, Cornelissen VA The effect of exercise training on blood pressure in African and Asian populations: A systematic review and meta-analysis of randomized controlled trials. Eur J Prev Cardiol. 2020; 27(5):457-72. [DOI:10.1177/2047487319871233]

[28] Voet NB, van der Kooi EL, van Engelen BG, Geurts AC. Strength training and aerobic exercise training for muscle disease. Cochrane Database Syst Rev. 2019; 12(12):CD003907. [DOI:10.1002/14651858. CD003907.pub5]

[29] Brooks SK, Webster RK, Smith LE, Woodland L, Wessely S, Greenberg $\mathrm{N}$, et al. The psychological impact of quarantine and how to reduce it: Rapid review of the evidence. Lancet. 2020; 395(10227):912-920. [DOI:10.1016/S0140-6736(20)30460-8]

[30] Toresdahl BG, Asif IM. Coronavirus disease 2019 (COVID-19): Considerations for the competitive athlete. Sports health. 2020; 12(3):221-4 [DOI:10.1177/1941738120918876] 
[31] González-Sanguino C, Ausín B, Castellanos MÁ, Saiz J, López-Gómez A, Ugidos $C$, et al. Mental health consequences during the initial stage of the 2020 Coronavirus pandemic (COVID-19) in Spain. Brain Behav Immun. 2020; 87:172-6. [DOI:10.1016/j.bbi.2020.05.040]

[32] Szabo A, Griffiths MD, Demetrovics Z. Psychology and exercise. In: Bagchi D, Nair S, Sen CK, editors. Nutrition and enhanced sports performance : Muscle building, endurance, and strength. United States: Academic Press; 2018. https://www.amazon.com/Nutrition-EnhancedSports-Performance-Endurance/dp/0128139226

[33] Arent SM, Walker AJ, Arent MA. The effects of exercise on anxiety and depression. Tenenbaum G, Eklund RC, editors. Handbook of sport psychology. United States: John Wiley \& Sons, Inc; 2020. [DOI:10.1002/9781119568124.ch42]

[34] Parfitt G, Hughes $S$. The exercise intensity-affect relationship: Evidence and implications for exercise behavior. J Exerc Sci Fit. 2009; 7(2):S34-41. [DOI:10.1016/S1728-869X(09)60021-6]

[35] Zhao JL, Jiang WT, Wang X, Cai ZD, Liu ZH, Liu GR. Exercise, brain plasticity, and depression. CNS Neurosci Ther. 2020; 26(9):885-95. [DOI:10.1111/cns.13385]

[36] Gorzi A, Rajabi H, Rajabi H, Azad A, Molanouri Shamsi M, Hedayati M. [Effect of concurrent, strength and endurance training on hormones, lipids and inflammatory characteristics of untrained men (Persian)]. IJEM. 2012; 13(6):614-29. https://www.sid.ir/en/journal/ViewPaper. aspx?id=275650

[37] Furnham A, Badmin N, Sneade I. Body image dissatisfaction: gender differences in eating attitudes, self-esteem, and reasons for exercise. $J$ Psychol. 2002; 136(6):581-96. [DOI:10.1080/00223980209604820]

[38] McDonald K, Thompson JK. Eating disturbance, body image dissatisfaction, and reasons for exercising: Gender differences and correlational findings. Int J Eat Disord. 1992; 11(3):289-92. [DOI:10.1002/1098108X(199204)11:3<289::AID-EAT2260110314>3.0.CO;2-F]

[39] Prichard I, Tiggemann M. Objectification in fitness centers: Selfobjectification, body dissatisfaction, and disordered eating in aerobic instructors and aerobic participants. Sex roles. 2005;53(1-2):19-28. [DOI:10.1007/s11199-005-4270-0]

[40] Jackson EM. Stress relief: The role of exercise in stress management. ACSMs Health Fit J. 2013; 17(3):14-9. [DOI:10.1249FIT.0b0 13e31828cb1c9]

[41] Bozkurt B, Kovacs R, Harrington B. HFSA/ACC/AHA statement addresses concernsre: Using RAAS antagonists in COVID-19 [Internet] 2020 [Updated 2020 March 17]. Availeble from: https://www.acc.org/ latest-in-cardiology/articles/2020/03/17/08/59/hfsa-acc-aha-statement-addresses-concerns-re-using-raas-antagonists-in-covid-19

[42] Shao Z, Schuster A, Borowski AG, Thakur A, Li L, Tang WHW. Soluble angiotensin converting enzyme 2 levels in chronic heart failure is associated with decreased exercise capacity and increased oxidative stress-mediated endothelial dysfunction. Transl Res. 2019; 212:80-8. [DOI:10.1016/j.trsl.2019.06.004]

[43] Channon KM. Exercise and cardiovascular health: New routes to reap more rewards. Cardiovasc Res. 2019; 116(5):e56-8. [DOI:10.1093/cvr/ cvz264]

[44] Bhaskarabhatla KV, Birrer R. Physical activity and diabetes mellitus. Compr Ther. 2005; 31(4):291-8. [DOI:10.1385/comp:31:4:291]

[45] Nystoriak MA, Bhatnagar A. Cardiovascular effects and benefits of exercise. Front Cardiovasc Med. 2018; 5:135. [DOI:10.3389/ fcvm.2018.00135]
[46] Marcus MD, Levine MD, Kalarchian MA, Wisniewski L. Cognitive behavioral interventions in the management of severe pediatric obesity. Cogn Behav Pract. 2003; 10(2):147-56. [DOI:10.1016/S10777229(03)80023-8

[47] Tayebi SM, ahmadi hekmatikar A, Ghanbari-Niaki A, Fathi R. [Ghrelin behavior in exercise and training (Persian)]. Razi J Med Sci. 2020; 27(1):85-111. http://rjms.iums.ac.ir/article-1-5803-en.html

[48] Ahmadi SM, Fathi M, RashidLamir A, Aminian F. [Effects of 8 weeks aerobic training on plasma ghrelin level and ghrelin lymphocyte gene expression in elderly men (Persian)]. Salmand. 2019; 13(4):494-505. [DOI: 10.32598/SIJA.13.4.494]

[49] Bird L. Exercise lowers leptin and leukocytosis. Nat Rev Immunol. 2020; 20(1):2-3. [DOI: 10.1038/s41577-019-0253-1]

[50] Khoramipour K, Ahmadi Hekmatikar A, Sotvan H. [A brief overview of fatmax and MFO in exercise (Persian)]. Razi J Med Sci. 2020; 27(3):49-59. http://rjms.iums.ac.ir/article-1-5959-fa.html

[51] Khosravi N, Hanson E, Farajivafa V, Agha-Alinejad H, Haghighat S, Molanouri Shamsi $\mathrm{M}$, et al. [Changes in monocyte populations following acute aerobic exercise in breast cancer survivors (Persian)]. Int J Behav Develop. 2018; 11(1):7-16. http://ijbd.ir/article-1-659-en.html

[52] Owen N, Sparling PB, Healy GN, Dunstan DW, Matthews CE, editors. Sedentary behavior: emerging evidence for a new health risk. Mayo Clin Proc. 2010; 85(12):1138-41. [DOI: 10.4065/mcp.2010.0444 ]

[53] Guo Y, Qiu P, Liu T. Tai Ji Quan: An overview of its history, health benefits, and cultural value. J Sport Health Sci. 2014; 3(1):3-8. [DOI: 10.1016/j.jshs.2013.10.004]

[54] Jakicic JM, Winters C, Lang W, Wing RR. Effects of intermittent exercise and use of home exercise equipment on adherence, weight loss, and fitness in overweight women: A randomized trial. JAMA. 1999; 282(16):1554-60. [DOI: 10.1001/jama.282.16.1554 ]

[55] Zhu W. Should, and how can, exercise be done during a coronavirus outbreak? An interview with Dr. Jeffrey A. Woods. J Sport Health Sci. 2020; 9(2):105-7. [DOI: 10.1016/j.jshs.2020.01.005 ]

[56] Mokhtarzade M, Ranjbar R, Majdinasab N, Patel D, Molanouri Shamsi M. Effect of aerobic interval training on serum IL-10, TNF $\alpha$, and adipokines levels in women with multiple sclerosis: Possible relations with fatigue and quality of life. Endocrine. 2017; 57(2):262-71. [DOI: $10.1007 / \mathrm{s} 12020-017-1337-y$ ]

[57] Molanouri Shamsi M, Chekachak S, Soudi S, Gharakhanlou R, Quinn LS, Ranjbar K, et al. Effects of exercise training and supplementation with selenium nanoparticle on T-helper 1 and 2 and cytokine levels in tumor tissue of mice bearing the 4 T1 mammary carcinoma. Nutrition. 2019; 57:141-7. [DOI: 10.1016/j.nut.2018.05.022]

[58] Friedrich MJ. Exercise may boost aging immune system. JAMA. 2008 299(2):160-1. [DOI: 10.1001/jama.2007.56-a]

[59] Wang J, Liu S, Li G, Xiao J. Exercise Regulates the Immune System. Adv Exp Med Biol. 2020; 1228:395-408. [DOI:10.1007/978-981-151792-1_27]

[60] Molanouri Shamsi M, Amani ShalamzariS. [Exercise Training, Immune System, and Coronavirus (Persian)]. Sport Physiol. 2020; 12(46):17-40. https://www.sid.ir/en/journal/ViewPaper.aspx?ID=761859

[61] Ahmadi Hekmatikar A, Haghshenas R, Mohammad Sadeghipor A. The effect of carbohydrate supplementation and pure water on interleukin 10 , glucose and hematological indexes in male football players. Sport Physiol Manage Investig. 2019; 11(4):135-45. http://www.sportrc.ir/ article_105715.html 
[62] Molanouri Shamsi M, Alinejad HA, Amani Shalamzari S, Aghayari A, Asghari Jafarabadi $M$, Talebi Badrabadi K. [Anti-inflammatory effects of a bout of circuit resistance exercise with moderateintensity in inactive obese males (Persian)]. JSSU. 2011; 19(5):598-609. http://jssu.ssu. ac.ir/article-1-1735-fa.html

[63] Walsh NP, Gleeson M, Shephard RJ, Gleeson M, Woods JA, Bishop NC, et al. Position statement part one: Immune function and exercise. Exerc Immunol Rev. 2011; 17:6-63. [PMID]

[64] Simpson RJ, Kunz H, Agha N, Graff R. Exercise and the regulation of immune functions. Prog Mol Biol Transl Sci. 2015; 135:355-80 [DOI:10.1016/bs.pmbts.2015.08.001]

[65] Campbell JP, Turner JE. Debunking the myth of exercise-induced immune suppression: Redefining the impact of exercise on immunological health across the lifespan. Front Immunol. 2018; 9:648. [DOI:10.3389/ fimmu.2018.00648]

[66] Pedersen BK, Rohde T, Zacho M. Immunity in athletes. J Sports Med Phys Fitness. 1996; 36(4):236-45. [PMID]

[67] Molanouri Shamsi M, Hassan ZM, Quinn LS, Gharakhanlou R, Baghersad L, Mahdavi M. Time course of IL-15 expression after acute resistance exercise in trained rats: Effect of diabetes and skeletal muscle phenotype. Endocrine. 2015; 49(2):396-403. [DOI:10.1007/s12020014-0501-x]

[68] Martin SA, Pence BD, Woods JA. Exercise and respiratory tract viral infections. Exerc Sport Sci Rev. 2009; 37(4):157-64. [DOI:10.1097/ JES.0b013e3181b7b57b] [PMCID]

[69] Phelan D, Kim JH, Chung EH. A game plan for the resumption of sport and exercise after coronavirus disease 2019 (COVID-19) infection. JAMA Cardiology. 2020; 5(10):1085-6. [DOI:10.1001/jamacardio.2020.2136]

[70] Bangsbo J, Mohr M, Poulsen A, Perez-Gomez J, Krustrup P. Training and testing the elite athlete. J Exerc Sci Fit. 2006; 4(1):1-14. https://portal. findresearcher.sdu.dk/en/publications/training-and-testing-theelite-athlete

[71] Fox SM, Naughton JP, Haskell WL. Physical activity and the prevention of coronary heart disease. Ann Clin Res. 1971; 3(6):404-32. [PMID]

[72] Garber CE, Blissmer B, Deschenes MR, Franklin BA, Lamonte MJ, Lee I-M, et al. American College of Sports Medicine position stand. Quantity and quality of exercise for developing and maintaining cardiorespiratory, musculoskeletal, and neuromotor fitness in apparently healthy adults: Guidance for prescribing exercise. Med Sci Sports Exerc. 2011; 43(7):1334-59. [DOI:10.1249/MSS.0b013e318213fefb]

[73] Tanaka H, Monahan KD, Seals DR. Age-predicted maximal heart rate revisited. J Am Coll Cardiol. 2001; 37(1):153-6. [DOI:10.1016/s07351097(00)01054-8] [PMID]

[74] Khoramipour K, Basereh A, Hekmatikar AA, Castell L, Ruhee RT, Suzuki K. Physical activity and nutrition guidelines to help with the fight against COVID-19. J Sports Sci. 2021; 39(1):101-7. [DOI:10.1080/02640414.2 020.1807089]

[75] Vetrovsky T, Steffl M, Stastny P, Tufano JJ. The efficacy and safety of lower-limb plyometric training in older adults: A systematic review. Sports Med. 2019; 49(1):113-31. [DOI:10.1007/s40279-018-1018-x] [PMCID]

[76] Chen P, Mao L, Nassis GP, Harmer P, Ainsworth BE, Li F. Wuhan coronavirus (2019-nCoV): The need to maintain regular physical activity while taking precautions. J Sport Health Sci. 2020; 9(2):103-4. [DOI:10.1016/j. jshs.2020.02.001] [PMCID]
[77] Halabchi F, Ahmadinejad Z, Selk-Ghaffari M . Covid-19 epidemic: Exercise or not to exercise; That is the question. Asian J Sports Med. 2020 11(1):e102630. [DOI:10.5812/asjsm.102630]

[78] Toresdahl BG, Asif IM. Coronavirus disease 2019 (COVID-19): Considerations for the competitive athlete. Sports Health. 2020; 12(3):221-4. [DOI:10.1177/1941738120918876] [PMCID]

[79] Pedersen BK, Saltin B. Exercise as medicine - evidence for prescribing exercise as therapy in 26 different chronic diseases. Scand J Med Sci Sports. 2015; 25(Suppl 3):1-72. [DOI:10.1111/sms.12581] [PMID]

[80] Norouzi E, Hosseini FS, Vaezmosavi M, Gerber M, Pühse U, Brand S Zumba dancing and aerobic exercise can improve working memory, motor function, and depressive symptoms in female patients with Fibromyalgia. Eur J Sport Sci. 2019; 20(7):981-91. [DOI:10.1080/17461391 .2019.1683610

[81] Gabriel H, Kindermann W. The acute immune response to exercise: What does it mean? Int J Sports Med. 1997; 18(Suppl 1):S28-45. [DOI:10.1055/s-2007-972698] [PMID]

[82] Radom-Aizik S. Immune response to exercise during growth. Pediatr Exerc Sci. 2017; 29(1):49-52. [DOI:10.1123/pes.2017-0003] [PMID]

[83] Timmons BW, Cieslak T. Human natural killer cell subsets and acute exercise: A brief review. Exerc Immunol Rev. 2008; 14:8-23. [PMID]

[84] Timmons BW. Exercise and immune function in children. Am J Lifestyle Med. 2007; 1(1):59-66. [DOI:10.1177/1559827606294851]

[85] Boas SR, Danduran MJ, McColley SA, Beaman K, O'Gorman MR. Immune modulation following aerobic exercise in children with cystic fibrosis. Int J Sports Med. 2000; 21(04):294-301. [DOI:10.1055/s-2000-311]

[86] Fallon K. Exercise in the time of COVID-19. Aust J Gen Pract. 2020 49(Suppl 13):1-2. https://cardiologiadoexercicio.com.br/wp-content/ uploads/2020/09/Exercicios-em-tempos-de-COVID-19.pdf

[87] Ravalli S, Castrogiovanni P, Musumeci G. Exercise as medicine to be prescribed in osteoarthritis. World J Orthop. 2019; 10(7):262-7. [DOI: 10.5312/wjo.v10.i7.262] [PMCID]

[88] Miles MP, Kraemer WJ, Grove DS, Leach SK, Dohi K, Bush JA, et al. Effects of resistance training on resting immune parameters in women. Eur J Appl Physiol. 2002; 87(6):506-8. [DOI:10.1007/s00421-002 0683-4]

[89] Calle MC, Fernandez ML. Effects of resistance training on the inflammatory response. Nutr Res Pract. 2010; 4(4):259-69. [DOI:10.4162/ nrp.2010.4.4.259] [PMCID]

[90] Pedersen BK, Steensberg A, Keller P, Keller C, Fischer C, Hiscock N, et al. Muscle-derived interleukin-6: lipolytic, anti-inflammatory and immune regulatory effects. Pflugers Arc. 2003; 446(1):9-16. [DOI:10.1007/ s00424-002-0981-z]

[91] Suzuki K. Cytokine Response to Exercise and Its Modulation. Antioxidants (Basel). 2018; 7(1):17.[ DOI:10.3390/antiox7010017]

[92] Stewart LK, Flynn MG, Campbell WW, Craig BA, Robinson JP, Timmerman $\mathrm{KL}$, et al. The influence of exercise training on inflammatory cytokines and c-reactive protein. Med Sci Sports Exerc. 2007; 39(10):1714-9. [DOI:10.1249/mss.0b013e31811ece1c]

[93] Raines C, Frosig T, Escobar KA, Cotter JA, Schick EE. Acute resistance exercise at varying volume loads does not enhance plasma interleukin-6. IJKSS. 2020; 8(1):37-42. http://www.journals.aiac.org.au/index.php/ IJKSS/article/view/5855 
[94] Xiao C, Beitler JJ, Higgins KA, Chico CE, Withycombe JS, Zhu Y, et al. Pilot study of combined aerobic and resistance exercise on fatigue for patients with head and neck cancer: Inflammatory and epigenetic changes. Brain Behav Immun. 2020; 88:184-92. [DOI:10.1016/j. bbi.2020.04.044]

[95] Scheffer DdL, Latini A. Exercise-induced immune system response: Anti-inflammatory status on peripheral and central organs. Biochim Biophys Acta Mol Basis Dis. 2020; 1866(10):165823. [DOI:10.1016/j. bbadis.2020.165823] [PMCID]

[96] Dixit S. Can moderate intensity aerobic exercise be an effective and valuable therapy in preventing and controlling the pandemic of COVID-19? Med Hypotheses. 2020; 143:109854. [DOI:10.1016/j. mehy.2020.109854] [PMCID]

[97] Highton PJ, White AEM, Nixon DGD, Wilkinson TJ, Neale J, Martin $\mathrm{N}$, et al. Influence of acute moderate- to high-intensity aerobic exercise on markers of immune function and microparticles in renal transplant recipients. Am J Physiol Renal Physiol. 2020; 318(1):F7685. [DOI: 10.1152/ajprenal.00332.2019]

[98] Sitlinger A, Brander DM, Bartlett DB. Impact of exercise on the immune system and outcomes in hematologic malignancies. Blood Adv. 2020; 4(8):1801-11. [DOI:10.1182/bloodadvances.2019001317] [PMCID]

[99] Nieman DC, Wentz LM. The compelling link between physical activity and the body's defense system. J Sport Health Sci. 2019; 8(3):20117. [DOI:10.1016/j.jshs.2018.09.009] [PMCID]

[100] de Souza DC, Matos VAF, dos Santos VOA, Medeiros IF, Marinho CSR, Nascimento PRP, et al. Effects of high-intensity interval and moderate-intensity continuous exercise on inflammatory, leptin, iga, and lipid peroxidation responses in obese males. Front Physiol. 2018; 9:567. [DOI:10.3389/fphys.2018.00567] [PMCID]

[101] Hajizadeh Maleki B, Tartibian B, Mooren FC, FitzGerald LZ, Krüger $\mathrm{K}$, Chehrazi $\mathrm{M}$, et al. Low-to-moderate intensity aerobic exercise training modulates irritable bowel syndrome through antioxidative and inflammatory mechanisms in women: Results of a randomized controlled trial. Cytokine. 2018; 102:18-25. [DOI:10.1016/j. cyto.2017.12.016]

[102] Durrer C, Francois M, Neudorf H, Little JP. Acute high-intensity interval exercise reduces human monocyte Toll-like receptor 2 expression in type 2 diabetes. Am J Physiol Regul Integr Comp Physiol. 2017; 312(4):R529-38. [DOI:10.1152/ajpregu.00348.2016] [PMCID]

[103] Szlezak AM, Szlezak SL, Keane J, Tajouri L, Minahan C. Establishing a dose-response relationship between acute resistance-exercise and the immune system: Protocol for a systematic review. Immunol Lett. 2016; 180:54-65. [DOI:10.1016/j.imlet.2016.10.010]

[104] Dorneles GP, Haddad DO, Fagundes VO, Vargas BK, Kloecker A, Romão PRT, et al. High intensity interval exercise decreases IL-8 and enhances the immunomodulatory cytokine interleukin-10 in lean and overweight-obese individuals. Cytokine. 2016; 77:1-9. [DOI: 10.1016/j.cyto.2015.10.003]

[105] Gomes EC, Florida-James G. Exercise and the Immune System. In: Esser C, editor. Environmental Influences on the Immune System. Vienna: Springer Vienna; 2016. https://www.springer.com/gp/ book/9783709118887

[106] Sarir H, Emdadifard G, Farhangfar H, TaheriChadorneshin H. Effect of vitamin $\mathrm{E}$ succinate on inflammatory cytokines induced by high-intensity interval training. J Res Med Sci. 2015; 20(12):1177-81. [DOI:10.4103/1735-1995.172986] [PMCID]
[107] Zwetsloot KA, John CS, Lawrence MM, Battista RA, Shanely RA. High-intensity interval training induces a modest systemic inflammatory response in active, young men. J Inflamm Res. 2014; 7:9-17. [DOI:10.2147/JIR.S54721] [PMCID]

[108] Gholamnezhad Z, Boskabady MH, Hosseini M, Sankian M, Khajavi Rad A. Evaluation of immune response after moderate and overtraining exercise in wistar rat. Iran J Basic Med Sci. 2014; 17(1):1-8. [PMCID]

[109] Neves PRDS, Tenório TRDS, Lins TA, Muniz MTC, Pithon-Curi TC, Botero JP, et al. Acute effects of high- and low-intensity exercise bouts on leukocyte counts. J Exerc Sci Fit. 2015; 13(1):24-8. [DOI:10.1016/j. jesf.2014.11.003] [PMCID]

[110] Zimmer P, Baumann FT, Bloch W, Schenk A, Koliamitra C, Jensen P, et al. Impact of exercise on pro inflammatory cytokine levels and epigenetic modulations of tumor-competitive lymphocytes in Non-HodgkinLymphoma patients-randomized controlled trial. Eur J Haematol. 2014 93(6):527-32. [DOI:10.1111/ejh.12395 ]

[111] Child M, Leggate M, Gleeson M. Effects of two weeks of high-intensity interval training (HIIT) on monocyte TLR2 and TLR4 expression in high BMI sedentary men. Int J Exerc Sci. 2013; 6(1):81-90. https://digitalcommons.wku.edu/cgi/viewcontent.cgi?article $=1485 \&$ context=ijes

[112] Rahmati M, Khazani A, Gharakhanlou R, Movaheddin M, Manahej $H$. [Chronic effects of moderate intensity endurance training on neuropathic pain symptoms in diabetic rats (Persian)]. Physiol Pharmacol. 2013; 16(4):435-45. http://irisweb.ir/files/site1/rds journals/26/article-26-5876.pdf

[113] Shirvani H, Ghahreman Tabrizi K, Sobhani V. [Effects of high intensity intermittent exercise on serum Immunoglobulin's and Complement system response in youth soccer players (Persian)]. J Birjand Univ Med Sci. 2013; 20(3):233-43. http://journal.bums.ac.ir/article-1-1331-en.htm|

[114] Navarro F, Bacurau AVN, Pereira GB, Araújo RC, Almeida SS, Moraes $M R$, et al. Moderate exercise increases the metabolism and immune function of lymphocytes in rats. Eur J Appl Physiol. 2013; 113(5):1343-52. [DOI: 10.1007/s00421-012-2554-y]

[115] Wright BJ, Eddy PJ, Kent S. Work stress, immune, and inflammatory markers. In: Bültmann U, Siegrist J, editors. Handbook of Socioeconomic Determinants of Occupational Health. Germany: Springer; 2020. https://www.amazon.com/Handbook-Disability-Health-Occupational-Sciences/dp/3030243354

[116] Segerstrom SC, Miller GE. Psychological stress and the human immune system: A meta-analytic study of 30 years of inquiry. Psychol Bull. 2004; 130(4):601-30. [DOI:10.1037/0033-2909.130.4.601] [PMCID]

[117] Felten SY, Felten DL. Neural-immune interactions. Prog Brain Res. 1994; 100:157-62. [PMID]

[118] Cohen S, Williamson GM. Stress and infectious disease in humans. Psychol bull. 1991; 109(1):5-24. [DOI:10.1037/0033-2909.109.1.5]

[119] Gouin JP. Chronic stress, immune dysregulation, and health. Am J Lifestyle Med. 2011; 5(6):476-85. [DOI:10.1177/1559827610395467]

[120] Kennedy PJ, Cryan JF, Quigley EMM, Dinan TG, Clarke G. A sustained hypothalamic-pituitary-adrenal axis response to acute psychosocial stress in irritable bowel syndrome. Psychol Med. 2014; 44(14):3123-34. [DOI:10.1017/S003329171400052X]

[121] Hightower LE, Santoro MG. Coronaviruses and stress: From cellular to global. Cell Stress Chaperones. 2020; 25(5):701-5. [DOI:10.1007/ s12192-020-01155-4 ]

[122] Kanneganti T-D, Dixit VD. Immunological complications of obesity. Nat immunol. 2012; 13(8):707-12. [DOI:10.1038/ni.2343] 
[123] de Heredia FP, Gómez-Martínez S, Marcos A. Obesity, inflammation and the immune system. Proc Nutr Soc. 2012; 71(2):332-8. [DOI:10.1017/S0029665112000092]

[124] Guilherme A, Virbasius JV, Puri V, Czech MP. Adipocyte dysfunctions linking obesity to insulin resistance and type 2 diabetes. Nat Rev Mol Cell Biol. 2008; 9(5):367-77. [DOI:10.1038/nrm2391] [PMCID]

[125] Feuerer M, Herrero L, Cipolletta D, Naaz A, Wong J, Nayer A, et al. Lean, but not obese, fat is enriched for a unique population of regulatory T cells that affect metabolic parameters. Nat Med. 2009; 15(8):930-9. [DOI:10.1038/nm.2002] [PMCID]

[126] Deng J, Liu S, Zou L, Xu C, Geng B, Xu G. Lipolysis response to endoplasmic reticulum stress in adipose cells. J Biol Chem. 2012; 287(9):6240-9. [DOI: 10.1074/jbc.M111.299115] [PMCID]

[127] Sartipy P, Loskutoff DJ. Monocyte chemoattractant protein 1 in obesity and insulin resistance. Proc Natl Acad Sci USA. 2003; 100(12):7265-70. [DOI: 10.1073/pnas.1133870100] [PMCID]

[128] Lagathu C, Yvan-Charvet L, Bastard JP, Maachi M, Quignard-Boulangé A, Capeau J, et al. Long-term treatment with interleukin-1beta induces insulin resistance in murine and human adipocytes. Diabetologia. 2006; 49(9):2162-73. [DOI:10.1007/s00125-006-0335-z]

[129] Weisberg SP, McCann D, Desai M, Rosenbaum M, Leibel RL, Ferrante Jr AW. Obesity is associated with macrophage accumulation in adipose tissue. J Clin Invest. 2003; 112(12):1796-808. [DOI:10.1172/JCI19246] [PMCID]

[130] Karlsson EA, Sheridan PA, Beck MA. Diet-induced obesity in mice reduces the maintenance of influenza-specific CD8+ memory T cells. J Nutr. 2010; 140(9):1691-7. [DOI:10.3945/jn.110.123653] [PMCID] 
This Page Intentionally Left Blank 